\title{
Either IOD Leading or ENSO Leading Triggers Extreme Thermohaline Events in the Tropical Central Indian Ocean
}

Jin Liu

Sun Yat-Sen University

Dongxiao Wang ( $\sim$ dxwang@scsio.ac.cn )

South China Sea Institute of Oceanology Chinese Academy of Sciences https://orcid.org/0000-00027782-0387

\section{Tingting Zu}

South China Sea Institute of Oceanology Chinese Academy of Sciences

Ke Huang

South China Sea Institute of Oceanology Chinese Academy of Sciences

Oscar Y. W. Zhang

Sun Yat-Sen University

\section{Research Article}

Keywords: Salinity anomalies, surface buoyancy fluxes, ocean dynamics, advection, tropical Indian Ocean

Posted Date: January 20th, 2022

DOI: https://doi.org/10.21203/rs.3.rs-1238657/v1

License: @ (i) This work is licensed under a Creative Commons Attribution 4.0 International License. Read Full License 
2

Jin LIU ${ }^{1,2}$, Dongxiao WANG ${ }^{1,2^{*}}$, Tingting $\mathrm{ZU}^{3}, \mathrm{Ke} \mathrm{HUANG}^{3}$, and Oscar Y. W. ZHANG ${ }^{1,2}$

\section{Either IOD leading or ENSO leading triggers extreme thermohaline events in the tropical central Indian Ocean}

$4 \quad{ }^{1}$ Southern Marine Science and Engineering Guangdong Laboratory (Zhuhai), Zhuhai, China

$5 \quad{ }^{2}$ School of Marine Sciences, Sun Yat-sen University, Zhuhai, China

$6{ }^{3}$ State Key Laboratory of Tropical Oceanography, South China Sea Institute of Oceanology,

7 Chinese Academy of Sciences, Guangzhou, China

8 *Corresponding Author: Dongxiao Wang (dxwang@mail.sysu.edu.cn)

9

10

11
Submitted to

Climate Dynamics

January 2022

\section{Key Points:}

- The causes of extremely high salinity anomalies in the tropical Central Indian Ocean from 2010 boreal autumn to 2011 boreal spring and from 2016 boreal autumn to 2017 boreal spring are analyzed and compared through the surface buoyancy fluxes and ocean dynamic processes.

- The possible physical linkages or mechanisms of related processes underlying the salinity anomalies are proposed. 


\section{Abstract}

Based on the 12-year (2007-2018) salinity data from Array for Real-Time Geostrophic Oceanography (ARGO), significantly positive salinity anomalies are found in the upper layer of the tropical central Indian Ocean (IO) from 2010 boreal autumn to 2011 boreal spring and from 2016 boreal autumn to 2017 boreal spring. Wind, precipitation, outgoing longwave radiation (OLR) and ocean currents from satellite and reanalysis data are utilized to analyze the atmospheric, ocean dynamic processes and the salinity budget associated with the high salinity events. The results indicate that surface buoyancy fluxes are not the dominant factor affecting the positive salinity anomalies, while ocean dynamic processes play a more important role. Under the influence of the La Niña and strong negative Indian Ocean Dipole (nIOD) in 2010 and 2016, positive salinity anomalies appear in the eastern IO at the end of 2010 and 2016 due to strong westerlies and positive zonal currents. But because the La Niña in 2010 is stronger than in 2016, the salinity anomalies in 2010 are stronger, and the decline in the following year is stronger and lasts longer, making the salinity anomalies gradually weakened. Therefore, the maximum value of the salinity anomalies in 2011 is in January, while in 2017 the salinity anomalies first decrease and then increase with the largest in March. Salinity budget analyses also show that ocean advection is the main factor leading to the salinity anomaly variations for these two periods. Among them, the changes of the zonal velocity in the zonal advection anomalies have the greatest impact. The zonal advection is positive and the strongest at the end of 2010 and negative in early 2011, but weak positive at the end of 2016. In early 2017 the zonal advection is first negative, then becomes positive and strengthens in spring, so salinity anomalies in 2017 spring is higher than that in 2011. The entrainment effect during 10A11S is more significant than 16A17S and the freshwater flux (FWF) has a small and negative effect on positive salinity anomalies for two events. The mutual effects of horizontal advection, FWF and vertical entrainment together lead to high salinity anomalies. The high salinity anomalies reflect the upper-ocean responses to climate events, which may also influence the regional air-sea interactions and large-scale processes.

Keywords: Salinity anomalies, surface buoyancy fluxes, ocean dynamics, advection, tropical Indian Ocean 


\section{Introduction}

Ocean salinity is an important aspect of the water mass property (Delcroix and Hénin, 1991). It is not only a key indicator of global hydrological cycle (Durack and Wijffels, 2010; Durack et al., 2012; Schmitt, 2008; Schmitt and Blair, 2015; Skliris et al., 2014), but also closely related to the ocean dynamics and thermodynamics (Lagerloef, 2002; Rao and Sivakumar, 2003; Ren and Riser, 2009). Salinity affects lots of aspects of ocean stability (Nyadjro et al., 2012; Schiller et al., 1997), dynamic ocean variability (Stammer, 1997; Sun et al., 2015; Thompson et al., 2006) and complicates air-sea interactions (Grunseich et al., 2013; Guan et al., 2014; Horii et al., 2016; Simon et al., 2006; Williams et al., 2010). With the development of the Argo project which provides more observations in the global ocean to conduct detailed studies on the water mass and related ocean dynamics, increasing numbers of salinity and temperature profiles have been collected for the upper $2000 \mathrm{~m}$ (Gould et al., 2004; Riser et al., 2008; Roemmich and Owens, 2000; Roemmich et al., 2009). These data offer an opportunity to examine the salinity variability and the related ocean dynamics in the Indian Ocean (IO; Jensen, 2003; Masson et al., 2004).

The tropical Indian Ocean (TIO) plays a unique role in the global climate system (Sharma et al., 2010; Subrahmanyam et al., 2011). The IO is rich in precipitation and has the most typical monsoon climate among the global ocean. In the equatorial Indian Ocean (EIO), strong westerlies dominate in boreal spring and autumn during the monsoon transition seasons around May and October-November, and drive the eastward surface currents, known as Wyrtki Jets (Wyrtki, 1973; Reppin et al., 1999). These jets trap the momentum from which the zonal winds input into the oceans in the upper $100 \mathrm{~m}$ and significantly influence the climate via horizontal heat, salt and mass transportation in the TIO (Murtugudde et al., 2000). Thermocline perturbations in the form of Rossby waves propagating westward from the southeastern TIO are able to influence the mixed layer through enhancing or depressing the entrainment and vertical mixing. These processes further affect salinity and trigger strong air-sea interactions (Du et al., 2009; Xie et al., 2002; Yokoi et al., 2012). In normal, salinity 
variations affect ocean stratification and air-sea heat flux in the IO, triggering a response in atmospheric circulation, which significantly influence the thermodynamics in the upper layer (Liang et al., 2018; Zeng and Wang, 2017). Moreover, these further lead to sea temperature variations and convection variations, which indirectly influence the intensity and development of the southwest monsoon and have great impacts on the IO and neighboring countries (Yadav et al., 2019; Sharma et al., 2020). Therefore, it is particularly important and necessary to study the salinity variability in the TIO.

Due to significant difference in salinity between the Arabian Sea and the Bay of Bengal, the upper layer salinity in the TIO is generally higher in the west and lower in the east. At the range of $20^{\circ} \mathrm{S}-10^{\circ} \mathrm{S}$, the Indonesian throughflow (ITF) and the south equatorial current (SEC) transport low salinity water to the western IO. Different mechanisms are found to be responsible for salinity variability at different depth and on different time scales. Surface salinity is largely controlled by surface freshwater flux (FWF), while upper layer salinity is also affected by horizontal advection, vertical entrainment, turbulence of mixing, diffusion and nonlinear effects (Hasson et al., 2013, 2014; Martins and Stammer, 2015). Interannual variability of salinity in the TIO is demonstrated to be closely related to the Indian Ocean Dipole (IOD; Grunseich et al., 2011; Zhang et al., 2013; Nyadjro and Subrahmanyam, 2014; Du and Zhang, 2015) and El Niño-Southern Oscillation (ENSO; Clarke and Liu, 1994; Meyers, 1996; Wijffels and Meyers, 2004; Feng et al., 2003, 2010), which are the important climate events that affect the coupled air-sea processes in the TIO (Schott et al., 2009; Phillips et al., 2021). Some studies have shown that these two interannual modes have significant impacts on IO dynamics by modulation of Walker circulation. Furthermore, IOD and ENSO events sometimes appear simultaneously (Saji and Yamagata, 2003; Stuecker et al., 2017). For example, positive IOD (pIOD) can co-occur with EI Niño, while negative IOD (nIOD) can co-occur with La Niña (Cai et al., 2009; Gnanaseelan et al., 2012; Hong et al., 2008). In addition, previous studies denoted that salinity variations might also be related to monsoon intensity. Zhang et al. (2020) found that the weakening of the monsoon intensity in the northern Arabian Sea from 2014 to 
2017 led to changes in ocean dynamics, which further resulted in a prolonged high salinity event.

Previous studies mainly focused on salinity variability and its relationship with precipitation and ocean processes in the TIO. Kido et al. (2019) concluded that positive sea surface salinity (SSS) anomalies in the southeastern TIO were primarily caused by reduction in precipitation and partly by enhanced evaporation due to increased wind speed, while negative SSS anomalies in the central-eastern EIO were generated by zonal advection anomalies induced by anomalous wind stress. On the other hand, subsurface salinity anomalies were almost entirely caused by wind stress effects mediated by ocean dynamical processes. Their results showed that large-scale ocean changes in response to the pIOD-related atmospheric anomalies were the key drivers of the observed salinity anomalies. Zhang et al. (2013) found different salinity variations in the EIO under the influence of pIOD and nIOD. The anomalous westward equatorial currents, attributed to anomalous easterlies, led to low salinity anomalies along the equator during the developing and mature phases of the pIOD events (Du and Zhang, 2015; Nyadjro and Subrahmanyam, 2014; Vinayachandran and Nanjundiah, 2009; Zhang et al., 2013). At the same time, intense northwestward currents off Sumatra strengthened the upwelling and westward high salinity advection near $10^{\circ} \mathrm{S}$ (Thompson et al., 2006). The anomalies during nIOD were opposite to those during pIOD events. In addition, the salinity variations are also significant during the decay phases and the following year of IOD events in the TIO where circulation system plays an important role in maintaining the heat and salt balance of the entire area, including the Wyrtki Jets and the SEC (Sun et al., 2019; Zhang et al., 2013; Li et al., 2018). ENSO teleconnection also induces anticyclonic (cyclonic) atmospheric circulation anomalies in the TIO when El Niño (La Niña) appears (Xie et al., 2002; Wang et al., 2003), such that the evolutions of ENSO are often associated with the development of the IOD. Grunseich et al. (2011) analyzed the surface salinity variations of the EIO when different IOD and ENSO phases occurred. The results showed that the development of IOD was affected according to whether El Niño and La Niña occurred, which further led to the salinity variability. The salinity variations 
observed throughout the EIO are largely explained by the dynamics responsible for dipole events. What's more, they feedback to the climate events-mainly through ocean stratification, barrier layer, temperature inversion, sea temperature and large-scale circulation and so on (Kido and Tozuka, 2017; Bhavani et al., 2017).

However, most of the previous studies concerned about the salinity variations under the influence of multiple climate events or the salinity variation processes during the development of a certain climate event. Sun et al. (2019) analyzed the evolution of salinity anomaly variations in the southwestern TIO (SWTIO) during 2010-2011 and concluded that the salinity variations were mainly affected by a nIOD event. During early 2011, the positive SSS anomalies shifted to the SWTIO through westward current anomalies. At the same time, the upwelling Rossby waves shoaled the thermocline and mixed layer depth, then brought the high salinity water from the subsurface into the surface layer. These processes further intensified the positive SSS anomalies. Du and Zhang (2015) investigated SSS variations in the TIO during July 2010-July 2014. During the nIOD events in 2010,2013, and 2014, their conclusions were similar to the analyses on nIOD above, while the processes reversed during the pIOD events in 2011 and 2012. Till now, there are few studies on the interannual anomalies of tropical central IO salinity and the mechanism comparison between two abnormal events of the same type. Therefore, it is very essential to study the mechanism reasons for the different performance of the same type of significantly anomalous salinity events at different periods. This study will also play a great role in predicting salinity variations in the IO under different climate events in the future.

Notably, we find that there are significantly positive salinity anomalies in 2017 based on the 6-year CTD observation data of the IO spring voyage, then the ARGO gridded data from 2007 to 2018 are also employed to confirm the phenomena (Figure 1): extremely high salinity anomalies are found in the tropical central IO from 2010 boreal autumn to 2011 boreal spring (hereafter 10A11S; i.e. from September 2010 to May 2011; Figure 1b) and from 2016 boreal autumn to 2017 boreal spring (hereafter 16A17S; i.e. from September 2016 to May 2017; Figure 1c). High salinity anomalies relative to the climatology derived from the Argo data during 2007-2018 reach above 
0.2 psu. According to the diagrams, $70^{\circ} \mathrm{E}-90^{\circ} \mathrm{E}, 10^{\circ} \mathrm{S}-0^{\circ}$ (black closed boxes in Figure 1) is the main high salinity anomalies area, so the area will be used as the research focus of the article. In addition, while positive salinity anomalies occur, negative temperature anomalies also appear though the location of the significantly negative anomalies are deviated from the significantly positive salinity anomalies (Figures 1e-f), they present a reverse relationship at the same time. During 10A11S there are strong positive salinity anomalies and negative temperature anomalies, but they are weaker during $16 \mathrm{~A} 17 \mathrm{~S}$. There is a good corresponding relationship between salinity and temperature. Hovmöller diagrams of salinity/temperature anomalies along the longitude and latitude indicate a clear positive-negative changing process from 2007 to 2018 (Figure 2). We find that the positive salinity anomalies do last for the periods of time during 10A11S and 16A17S (red boxes in Figure 2). There are extremely high salinity anomalies in these two periods with some differences in intensity and location, as are the two significantly negative temperature anomalies (contours in Figure 2). The results above suggest that the salinity anomalies of the former are stronger than the latter, the range of the anomalies are also larger and the time for the salinity anomaly events to reach the maximum is different. However, for the salinity anomalies in the tropical central IO during 10A11S and 16A17S, their spatial characteristics and formation mechanisms are not well studied, and the processes that cause the positive salinity anomalies are still unclear. Since the end of 2010 and the end of 2016 are the development period of nIOD and La Niña, the periods from January to May in 2011 and 2017 are in the recession year of nIOD and La Niña, we will investigate the salinity variations associated with climate events in the tropical central IO during 10A11S and 16A17S.

In this study, we combine salinity data from various datasets and other satellite and reanalysis data to analyze the influence of surface buoyancy fluxes and ocean dynamics on salinity anomalies mentioned above. We explore the underlying dynamics of the extremely high salinity anomalies in the tropical central IO during $10 \mathrm{~A} 11 \mathrm{~S}$ and $16 \mathrm{~A} 17 \mathrm{~S}$ and further quantitative analyze the mechanisms for the phenomenon by salinity budget equation. The remainder of this study is organized as 
follows: the data and methods used are described in Section 2. The results are presented in Section 3. Section 3.1 is mainly about spatial characteristics of the extremely high salinity anomalies. Section 3.2 is mainly about the salinity anomaly variations caused by surface buoyancy fluxes and Section 3.3 mainly denotes anomalies caused by ocean dynamics, which are modulated by related large-scale climate events. Section 3.4 indicates the quantitative analyses of the contribution of each item in the salinity budget equation that causes the anomalous salinity variations during 10A11S and 16A17S. In final, Section 4 gives the discussion and presents the summary of the study.

\section{Data and Methods}

\subsection{Data}

In the study, the Scripps Institution of Oceanography gridded monthly Argo products are used to analyze the salinity variability during 2007-2018. The Argo datasets have a horizontal resolution of $1^{\circ} \times 1^{\circ}$ at each standard pressure level. The L3 V5.0 Soil Moisture Active Passive (SMAP) SSS produced by NASA's Jet Propulsion Laboratory (Fore et al., 2020) is used. The SMAP SSS data have a spatial resolution of $0.25^{\circ}$ and is available from April 2015 to 2018. We also use European Centre for Medium-Range Weather Forecasts (ECMWF) Ocean Reanalysis System 5 (ORAS5) salinity data with a horizontal resolution of $1^{\circ} \times 1^{\circ}$ and a near-surface resolution of $1 \mathrm{~m}$ in the vertical during 2007-2018. In addition, we also download the simple ocean data assimilation (SODA) salinity data from 2007 to 2015 for salinity comparison and their resolution are $0.5^{\circ} \times 0.5^{\circ}$. Here, we use another composite SSS level-3 OS debiased products operationally generated by the Centre Aval de Traitement des Données SMOS (Soil Moisture and Ocean Salinity), which is the water mission of European Space Agency (ESA). Their salinity products are the first-of-its-kind spaceborne mission dedicated to this parameter. Surface salinity has been identified as one of the essential climate variables by Global Climate Observing System program. The nominal requirements for SMOS retrieval are to achieve a 0.1 accuracy (in practical 
salinity scale), over time/space scales of 10-30 days/200 km (Mecklenburg et al., 2008; Font et al., 2010).

Furthermore, in situ CTD measurements data for the IO voyage in the spring of 2014-2019 are also used. The data are mainly analyzed by two sections: across $0^{\circ}$ (equator) section between $80^{\circ} \mathrm{E}$ and $92^{\circ} \mathrm{E}$ and across $80^{\circ} \mathrm{E}$ section between $6^{\circ} \mathrm{S}$ and $2^{\circ} \mathrm{N}$. Comparing the salinity data of CTD, Argo and ORAS5 in these two sections, the spatial correlation coefficients are mostly greater than 0.5 (figure not shown). Figure 3 shows the average salinity change trend of the two sections. They have large correlation coefficients and relatively small root mean square errors (RMSEs), i.e. there are obvious consistencies between these types of data.

The Global Precipitation Climatology Project (GPCP) Version 2.3 monthly data with a resolution of $2.5^{\circ} \times 2.5^{\circ}$ are supported by NOAA Climate Data Record (CDR) Program, which are available since 1979 (Adler et al., 2003; Huffman et al., 2009) and evaporation with a resolution of $1^{\circ} \times 1^{\circ}$ from the objectively analyzed air-sea heat fluxes (OA Flux; Yu and Weller, 2007) are used to calculate surface FWF. The flux is mapped on to a $1^{\circ} \times 1^{\circ}$ grid using linear interpolation, which it is by re-griding the GPCP data onto OA Flux data.

In addition, we use the Oceanic General Circulation Model (OGCM; Masumoto et al., 2004; Sasaki et al., 2004) for the Earth Simulator (OFES) model to get the ocean current data. OFES is forced by National Centers for Environmental Prediction (NCEP) winds and has a horizontal resolution of $0.1^{\circ} \times 0.1^{\circ}$ with 54 vertical levels. It is based on the Modular Ocean Model Version 3 and run with climatological forcing for 50 years. Moreover, NCEP monthly pressure $10-1000 \mathrm{hPa}$ wind fields with a resolution of $2.5^{\circ} \times 2.5^{\circ}$ are also used to analyze wind anomalies.

The IOD is characterized by the dipole mode index (DMI) which is defined as the difference of area-averaged sea surface temperature anomaly (SSTA) between the western $\left(50^{\circ} \mathrm{E}-70^{\circ} \mathrm{E}, 10^{\circ} \mathrm{S}-10^{\circ} \mathrm{N}\right)$ and eastern $\left(90^{\circ} \mathrm{E}-110^{\circ} \mathrm{E}, 10^{\circ} \mathrm{S}-0^{\circ}\right)$ TIO (Saji et al., 1999). The ENSO is characterized by the Oceanic Niño Index (ONI) which is defined as the area-averaged SSTA in the Niño 3.4 region $\left(120^{\circ} \mathrm{W}-170^{\circ} \mathrm{W}, 5^{\circ} \mathrm{S}-5^{\circ} \mathrm{N}\right)$. We use SST anomaly data from NOAA Extended Reconstructed Sea Surface Temperature 
version 5 (ERSSTv5) with a resolution of $2^{\circ} \times 2^{\circ}$ to calculate ONI and DMI indexes. Then we choose \pm 0.5 times the standard deviation as their thresholds.

Except for the general features of salinity, all the anomalous data in the study are obtained by subtracting the climatological annual cycles from the monthly time series during 2007-2018. Most data are all monthly means and downloaded from the Asia-Pacific Data-Research Center of the International Pacific Research Center at the University of Hawaii (http://apdrc.soest.hawaii.edu).

\subsection{Data validation}

To validate the accuracy of the salinity data, we make a comparison between the Argo, ECMWF ORAS5, SMAP and SODA salinity datasets from 2007 to 2018. The spatial distributions of these salinity are similar (figure not shown): the salinity is higher in the west than in the east and gradually decreases from northwest to southeast. To quantify the comparison, we derive the spatial average salinity anomalies for time series analysis (Figure 4) and spatial distributions of salinity RMSEs between Argo data and other salinity data (Figure 5). The Argo salinity anomalies area-averaged compare well with that for ECMWF ORAS5, the SODA and SMAP data. Their curves are very close (Figure 4). The area-averaged correlation coefficients and RMSEs between the Argo and SMAP are respectively 0.9654 and 0.1181 psu, between the Argo and ECMWF ORAS5 are respectively 0.9879 and 0.0362 psu and between the Argo and SODA are respectively 0.9817 and 0.0376 psu. We can also find that the salinity RMSEs between Argo and other data are relatively small in the IO (Figure 5), especially in the main high salinity anomalies area (see black boxes in Figure 1), indicating the reliability of the Argo data. In general, all comparisons indicate good agreement between the Argo salinity and other datasets. And the two data of Argo and ECMWF ORAS5 have the highest similarity and the smallest RMSE so later we will use ECMWF ORAS5 salinity data to calculate the salinity budget equation.

\subsection{Methods}


To identify the key processes governing the evolution of salinity anomalies, salinity budget analysis has been widely used. The salinity budget equation (Gao et al., 2014; Qu et al., 2013) can be written as:

$$
\frac{\partial[S]}{\partial t}=-\frac{(P-E)}{h}[S]-\nabla_{H}(u S, v S)-\frac{1}{h}\left([S]-S_{-h}\right) w_{e}-\partial_{Z}(w S)+\varepsilon
$$

where the square bracket means the depth average within the selected depth. For instance, $[S]$ means the average salinity above $50 \mathrm{~m} . \frac{\partial[S]}{\partial t}$ is the salinity tendency; $\mathrm{P}$ and $\mathrm{E}$ are the precipitation and evaporation, $\mathrm{h}$ is taken as $50 \mathrm{~m} ; u, v$ and $w$ are the zonal, meridional and vertical velocities; and $S_{-h}$ is chosen as the salinity $15 \mathrm{~m}$ below the selected depth base (Ren et al., 2011). The subscript $\mathrm{H}$ and $\mathrm{Z}$ denote horizontal and vertical components of the variables, respectively. $\nabla_{H}=\left(\frac{\partial}{\partial x}, \frac{\partial}{\partial y}\right)$ and $\partial_{Z}=\left(\frac{\partial}{\partial z}\right)$ represent for the horizontal and vertical gradient operators, respectively. In the following, the first and second terms of equation on the right-hand side represent the surface FWF and the horizontal advection, respectively. Horizontal advection is divided into zonal advection and meridional advection. Vertical entrainment terms consist of the third and fourth terms on the right-hand side. The research combines the vertical entrainment terms with horizontal advection and calls it S-adv. The horizontal and vertical mixing and the accumulation of errors from the other terms are added into the residual term $\varepsilon$. We nominally consider the salinity and temperature at $10 \mathrm{~m}$ (first level) as that from the sea surface.

The entrainment velocity $w_{e}$ is calculated as $w_{e}=h\left(\frac{\partial u}{\partial x}+\frac{\partial v}{\partial y}\right)$. In addition, the residual term $\varepsilon$ is calculated by the salinity tendency minus the sum of FWF and S-adv. To separate the interannual variability from the seasonal cycle, each variable is divided into two parts: the climatological mean seasonal cycle and the anomaly variability separated from the seasonal cycle (e.g., $u=\bar{u}+u^{\prime}$ ). Thus, by neglecting the higher-order nonlinear terms, the salinity horizontal advection term (Zhang et al., 2013) in the above equation can be rewritten as

$$
-\nabla_{H}(u S, v S)=-\left(\bar{u} \frac{\partial[S]^{\prime}}{\partial x}+u^{\prime} \frac{\partial \overline{[S]}}{\partial x}+\bar{v} \frac{\partial[S]^{\prime}}{\partial y}+v^{\prime} \frac{\partial \overline{[S]}}{\partial y}\right)
$$


In the equation, the horizontal advection term contains two parts: One is due to the

312 variability of ocean current (e.g., $-u^{\prime} \frac{\partial \overline{[S]}}{\partial x}$ ), the other is due to the variability of 313 salinity gradient (e.g., $\left.-\bar{u} \frac{\partial[S]^{\prime}}{\partial x}\right)$.

\section{Results}

\subsection{Spatial characteristics of extremely high salinity anomalies}

Figure 6 shows the monthly Argo area-averaged salinity/temperature variations and their anomalies with depth from 2007 to 2018. According to what we have learned before, salinity refers to the frequent low salinity events within the upper $50 \mathrm{~m}$ of the entire periods due to the influence of surface FWF. In particular, extremely high salinity anomalies and a depth of approximately above $50 \mathrm{~m}$ are clearly identified during 10A11S and 16A17S (Figure 6b). Their intensities and the development trends of salinity anomalies are different. In addition, when positive salinity anomalies occur, significantly negative temperature anomalies also appear (contours in Figure 6b). Normally, we propose that salinity anomalies are mainly within $50 \mathrm{~m}$ of the upper layer. Compared with other low salinity events, such extremely high salinity anomalies during these two periods are uncommon. Furthermore, strong temporal correspondence between life cycle of salinization events in these two periods clearly indicates the dominance of these events on interannual variability of salinity in the tropical central IO. It is worth mentioned here that out of 12 years of study (figure not shown), only these two periods show abnormally strong salinization events. Hence, we mainly focus on these two extremely high salinity anomalies in the tropical central IO and the factors responsible for their formations.

Concerning about the spatial distributions of three-month moving mean extremely high salinity anomalies in the main high salinity anomalies area (see black boxes in Figure 1) during 10A11S and 16A17S (shading in Figure 7), the high value centers are different among all periods. In 10A11S (Figures 7a-c), the positively high salinity anomalies first appear in the eastern IO, then gradually become stronger, and finally decrease, with the strongest in January. While in 16A17S (Figures 7d-f), the 
positive salinity anomalies are relatively small first, then gradually become larger with the strongest in March. Comparing two events during 10A11S and 16A17S, the salinity anomalies in former have a more obvious tendency to move westward and southward. The latter tends to extend eastward in the later period. Obviously the intensity of the former event is greater than that of the latter from September to February, but the latter is slightly stronger in March-May.

Based on previous studies, the salinity anomaly variations are mainly related to two factors: surface buoyancy fluxes and ocean dynamics. Among them, the ocean dynamic processes are mainly caused by the climate modes, such as IOD and ENSO. Figure 8 gives the time series of the ONI and DMI indexes and the correlation coefficients between ONI/DMI and salinity anomalies during 2007-2018. We can find that salinity anomalies in the research area are negatively correlated with ENSO and IOD, and the correlation coefficients reach the maximum when the salinity anomalies lag ENSO by 3 months and IOD by 4 months, which are -0.4178 and -0.4610 , respectively. Furthermore, the development processes of climate events in 2010-2011 and 2016-2017 are different. 2010 is a strong La Niña year, which reaches maturity at the end of 2010 and begins to decline in 2011. In contrast, 2016 is a weaker La Niña year, basically close to normal. For IOD events, both 2010 and 2016 are strong nIOD years, but the nIOD in 2016 lasts longer. And in the first half of 2017, it shows a weaker pIOD. But weak pIOD only appears in the second half of 2011. To sum up, the La Niña in 2016 is much weaker than in 2010, but IOD events in 2016-2017 is little stronger than that in 2010-2011. According to the negative correlation coefficients between ENSO/IOD and salinity anomalies, there may be positive salinity anomalies caused by co-occurrence of IOD and La Niña during 10A11S and 16A17S. Later, we will focus on analyzing how climate models affect the salinity anomaly variations.

From the discussions above, two obvious positive salinity anomalies can be found during 10A11S and 16A17S. The development processes and intensities of the two anomalies are different and they may all be influenced by surface buoyancy fluxes and ocean dynamic processes. Next, we separately analyze the impact and contributions of these two factors on the salinity anomalies in the tropical central IO 
during 10A11S and 16A17S.

\subsection{Salinity anomaly variations caused by surface buoyancy fluxes}

From the analyses above, there are significantly high salinity anomalies during 10A11S and 16A17S. We first analyze the positive salinity anomaly variations caused by the surface buoyancy fluxes in the main high salinity anomalies area during $10 \mathrm{~A} 11 \mathrm{~S}$ and $16 \mathrm{~A} 17 \mathrm{~S}$.

Figure 9 shows the spatial distributions of cumulative precipitation anomaly and surface FWF in three months during 10A11S and 16A17S. There are two obviously and anomalously high precipitation centers in 2010 autumn (contours in Figure 9a) and 2017 spring (contours in Figure 9f), indicating that the precipitation is large for these two periods and small for other times. Moreover, the locations of large precipitation are mainly east of $82^{\circ} \mathrm{E}$. So, there is more precipitation in 2010 autumn than 2016 autumn and in 2017 spring than 2011 spring. Furthermore, the abnormal values of evaporation during $10 \mathrm{~A} 11 \mathrm{~S}$ and $16 \mathrm{~A} 17 \mathrm{~S}$ are small and the difference in evaporation between the two periods is also very small (figure not shown). The net surface FWF (shading in Figure 9) obtained by subtracting precipitation from evaporation is roughly the opposite of precipitation anomaly distributions. In other words, the net surface FWF in 2010 autumn is smaller than 2016 and in 2017 spring is smaller than 2011, which these two periods have more significantly negative values. According to the previous analyses, the area is also a corresponding high salinity anomalies area, the salinity anomalies during 10A11S (see Figures 7a-c) first increase, then decrease gradually and the strongest is in January. The salinity anomalies during 16A17S (see Figures 7d-f) first increase, then decrease and finally increase, with the strongest in March. The salinity anomalies in 2010 autumn are higher than 2016 autumn and in 2017 spring are higher than that 2011 spring. But the FWF in 2010 autumn is also stronger than that in 2016 autumn and in 2017 spring is stronger than that 2011 spring. The FWF variations in these two periods are not corresponding to the salinity anomalies during the same period. Therefore, FWF does not make a significant contribution to salinity variations. The above analyses show that the high 
salinity anomalies cannot be explained by FWF, so the extremely high salinity anomalies are not only determined by the surface buoyancy fluxes and they have a small effect, but also by other ocean dynamic processes.

According to the positive salinity anomalies corresponding to the negative temperature anomalies, it is further inferred that during $10 \mathrm{~A} 11 \mathrm{~S}$, there is no obvious upwelling at the beginning in the tropical central IO area, so it is beneficial to maintain higher temperature in the upper layer, promoting the occurrence of convection, and further lead to increase in precipitation (Figure 9a). In the later stage, the situation is reversed. Similarly, the situations during $16 \mathrm{~A} 17 \mathrm{~S}$ show that the precipitation is small first, and later precipitation becomes large due to the convection processes caused by SSTA (Figure 9f). Normally, because the precipitation in 2010 autumn and 2017 spring is larger than that the corresponding period in 2011 and 2016, it should cause the positive salinity anomalies in the former periods to be smaller than that in the latter periods, but in fact it's the opposite. Therefore, the above results indicate that the main reason of the positive salinity anomalies is not surface buoyancy fluxes. Another factor should be responsible for the salinity anomalies in the tropical central IO. Ocean dynamic processes may contribute more to the extremely high salinity anomalies. Next, our studies focus on the impacts of ocean dynamics on extremely high salinity anomalies in the tropical central IO for these two periods.

\subsection{Salinity anomaly variations caused by ocean dynamics}

We have analyzed surface buoyancy fluxes and initially conclude that it is not the main cause of the extremely high salinity anomalies. As mentioned above, the ocean dynamic processes that cause salinity variations may be related to large-scale dynamic processes such as IOD and ENSO (see Figure 8). Then, let's analyze how the climate modes modulate the ocean dynamic processes, which in turn affect the salinity anomalies.

Figure 10 and 11 show the evolution of monthly mean salinity anomalies and the related processes during 10A11S and 16A17S, respectively. During 
September-November (Figures 10a-c and 11a-c), the zonal wind anomalies in the EIO is positive, indicating that there are abnormal westerlies at this time. And the anomalies in 2010 are stronger than that in 2016. According to the previous analysis, 2010 and 2016 are nIOD and La Niña years. La Niña in the tropical Pacific leads to an increase in the Walker circulation and the effect of atmospheric bridges also increases the Walker circulation in the TIO. Therefore, for the strong La Niña year in 2010, the counterclockwise circulation in the TIO has strengthened, and there are stronger westerly anomalies. During the same period of 2016, it is mainly the process of changing from the southwesterlies to the westerlies, which result in stronger eastward currents in 2010 than in 2016 and further lead to the intrusion of high salinity water from the west to the east in the TIO. Thus, under the influence of strong westerlies and eastward currents, the salinity anomalies in September-November 2010 are higher than the corresponding months in 2016. It can be seen from the contours in Figures 10b-c that the high salinity anomalies in 2010 can reach the coast of Sumatra Island in the eastern IO and above 0.4 psu. This is related to the facts mentioned earlier (see Figure 8), the La Niña in 2010 is much stronger than in 2016 and the intensities of nIOD are similar in two years. Hence through the co-occurrence of stronger La Niña and nIOD in 2010, Walker circulation becomes stronger and leads to stronger westerlies, which in turn result in stronger eastward currents, then these currents further cause extremely high salinity anomalies in the central-eastern TIO. However, through the co-occurrence of much weaker La Niña and nIOD in 2016, weak Walker circulation causes weak eastward currents and positively low salinity anomalies in the central-eastern TIO. According to previous studies, during nIOD and La Niña years, the anomalous westerlies diverge to the south off the south Java-Lesser Sunda coast. The positive wind stress curls trigger anomalous cyclonic circulation in the southeastern IO and forced upwelling Rossby waves to slowly propagate westward. Evidently, it is more significant in 2010 than in 2016.

During December-February of the following year, the central-eastern EIO zonal wind anomalies weaken (Figures 10d-f and 11d-f). So as the westerly anomalies weaken and it is mainly the process of changing from the westerlies to the 
northwesterlies, the eastward currents near the equator also weaken and even the eastward currents turn into westward currents. They are more obvious in 2011. As a result, affected by the extremely high salinity anomalies in the eastern IO caused by the eastward currents under the combined action of strong La Niña and nIOD in the early stage, the high salinity water is transported westward, which leads to the high salinity anomalies in the tropical central IO. From the high salinity anomalies center (contours in Figures 10d-f) we can see the trends of high salinity anomalies gradually moving westward. In 2017, affected by the weak positive salinity anomalies in the eastern IO caused by the weaker eastward currents under the combined action of weak La Niña and nIOD in the early stage and now weaker westward currents, the high salinity anomalies do not move significantly westward. These phenomena are mainly caused by the weakening of La Niña and nIOD events of different intensities. At the same time, the eastward Kelvin waves generated by the westerlies in October reach the east coast and reflect to form westward propagating upwelling Rossby waves. Due to the influence of upwelling Rossby waves, the lower layer of higher salinity water is transported upwards, which has a positive contribution to the salinity anomalies. Because the La Niña was stronger in 2010 than in 2016, the high salinity in former caused by vertical entrainment at this time is also stronger than the latter. Thus, the salinity anomalies begin to gradually decrease due to the decline of climate events and the salinity anomalies in these three months of 2011 are higher than that of 2017.

During March-May, La Niña in 2011 is still in a recession. The easterly anomalies are mainly on the equator in 2011, especially from April to May, while in 2017 there are obvious westerly anomalies. So, in 2011(Figures 10g-i) there are still westward currents and the upwelling Rossby waves caused by the previous period continue to move westward, which cause the positive salinity anomalies to gradually move westward and southward. And the positive salinity anomalies decrease in the tropical central IO. In 2017 (Figures 11g-i), due to the weak La Niña in 2016, ENSO has gradually become normal during this period. The easterlies become westerlies and they are clearly stronger in April. The westward currents turn into eastward currents, which result in positive salinity anomalies in the tropical central IO. Therefore, at this 
time the positive salinity anomalies in 2017 are stronger than in 2011.

IOD may modulate the equatorial winds and then affects the related wave processing. It also shows direct influence on the high salinity events. According to previous researches (Izumo et al., 2008; Yokoi et al., 2008), Seychelles Dome (SD; $60^{\circ} \mathrm{E}-80^{\circ} \mathrm{E}, 10^{\circ} \mathrm{S}-5^{\circ} \mathrm{S}$ ) is a remarkable oceanic thermal dome along monsoon and southeasterlies. Due to its unique location, which is under the joint control of monsoon and southeasterlies, SD has a semi-annual cycle associated with upwelling in the boreal spring. Above the SD, SSTAs are sensitive to variability in the upwelling and these are especially so in their seasonal and interannual variation (Tozuka et al., 2010). Yokoi et al. (2012) used an ocean general circulation model (OGCM) to analyze seasonal and interannual variations of the SST above the SD. Their results indicated the SSTA in the SD was closely related to IOD. The pIOD (nIOD) might induce the weakened (strengthened) SD. Since 2010 and 2016 are nIOD years, there will be strong SD in 2011 spring and 2017 spring, so there is strong upwelling in the $60^{\circ} \mathrm{E}-80^{\circ} \mathrm{E}, 10^{\circ} \mathrm{S}-5^{\circ} \mathrm{S}$ that causes cold and salty water in the lower layer to be transported upward. In 2011 spring, high salinity water caused by upwelling will move towards the western IO under the influence of the westward currents. While in 2017 spring, the strong eastward currents cause the high salinity water to move eastward, which have contributions to the positively high salinity anomalies in the tropical central IO.

Between the two extremely high salinity anomaly events analyzed (i.e. 2012-2016; see Figure 2), there are significantly negative salinity anomalies, which are in a freshening stage, especially from 2011 autumn to 2013 spring (hereafter 11A13S) and from 2015 autumn to 2016 summer (hereafter 15A16S) are the most obvious. According to Figure 8, 2011 is a weak pIOD year with weak La Niña and 2012 is a strong pIOD year without El Niño or La Niña, while 2015 is a strong pIOD year with strong El Niño. By comparison, the previous significantly negatively low salinity event occurs in pIOD year without strong El Niño and the latter occurs in a strong El Niño and pIOD year. Through analyzing the salinity anomalies and related processes during 15A16S in Figure 12, it is just the opposite of 2010-2011 analyzed 
previously (see Figure 10). On the one hand, under the influence of strong pIOD at the end of 2015, the westward currents caused by the abnormal easterlies result in significantly negative salinity anomalies in the central-eastern IO (contours in Figure 12). Moreover, when El Niño occurs, the Walker circulation weakens, leading to a weakening of the clockwise circulation formed under the influence of pIOD. It further causes abnormal salinity weakening, but its impact is relatively small compared to pIOD. On the other hand, the negative wind stress curls in the southeastern IO trigger anticyclonic circulation, which lead to the downwelling Rossby waves to propagate westward. Similarly, the same phenomenon occurs during 11A13S (figure not shown). The IOD intensities for 11A13S and 15A16S are similar, but no El Niño occurred during $11 \mathrm{~A} 13 \mathrm{~S}$, so the salinity anomalies caused by the above are stronger than 15A16S. Therefore, the salinity of the central-eastern TIO also shows significantly negative anomalies in some years, indicating a major influence of climate events on salinity anomalies, highly consistent with the positive salinity anomalies in 2010-2011 and 2016-2017 by the analyses above.

Besides, weak positive salinity anomalies are found in the autumn of 2013 (see Figure 2), which do not fully develop and disappear soon. Looking at Figure 8, we find that 2013 is a weaker nIOD year than the intensities of nIOD in 2010 and 2016, and there is no El Niño or La Niña. Under such ocean dynamic condition, the abnormal westerlies caused by nIOD are very weak, leading to weak eastward currents, so the positive salinity anomalies are very small and quickly decline. Generally speaking, the periods from 2012 to 2016 are mainly the stage of salinity freshening. In 2010, nIOD causes positive salinity anomalies in the tropical central IO during 10A11S, pIOD in 2011 and 2012 causes negative salinity anomalies in the tropical central IO during 11A13S. pIOD in 2015 leads to negative salinity anomalies during 15A16S and nIOD in 2016 leads to positive salinity anomalies during 16A17S in the tropical central IO.

In addition, La Niña event as strong as 2010 that occurs during 2007 without an nIOD event does not produce any significantly positive salinity anomaly in 2007-2008 (see Figure 8). Further based on the above results, we also analyze the relationships 
between the salinity anomalies in the tropical central IO from 1979 to 2018 based on ECMWF ORAS5 data and IOD/ENSO. Comparing 1998, 2010 and 2016: 1998 and 2010 have similar La Niña intensities, but in 2010 the nIOD is stronger, and the resulting salinity is abnormally stronger; While the La Niña intensity in 2016 is significantly weaker than 1998, but the nIOD intensity is stronger, resulting in abnormally stronger salinity in 2016-2017. Comparing 1997, 2015 with 1994, 2006 : strong El Niño occurred in the first two years and weak El Niño occurred in the second two years, but the negative salinity anomalies in former are weaker than the latter; And comparing 1982 with 2015: both two years have similar pIOD intensities. Among them, a strong El Niño occurs in 1982 and a much stronger El Niño occurs in 2015. The salinity anomalies are the opposite of the El Niño strength. In 1982 it causes strong negative salinity anomalies and in 2015 it leads to weak negative salinity anomalies.

The above multiple analyses indicate that the interannual variability of oceanic and atmospheric conditions associated with IOD may be playing a crucial role on the modulation of salinity variability in the tropical central IO. ENSO has a certain influence on its anomalous salinity intensity. When IOD events of similar intensity occur, ENSO events of different intensities will cause an abnormal salinity difference. Our results show some resemblance with the finding of Zhang et al., (2013), such as, the interannual variability of salinity in the TIO was primarily controlled by IOD events rather than ENSO events and the opinions of previous studies (Burns and Subrahmanyam, 2016) that IOD events seemed to be the dominant influence on salinity during peak IOD months of co-occurring event years.

As a result, with the influence of different intensities of La Niña and nIOD events, the salinity variations and the related processes show different characteristic during $10 \mathrm{~A} 11 \mathrm{~S}$ and $16 \mathrm{~A} 17 \mathrm{~S}$. Given the typical displacement of the salinity front in the tropical central IO when climate events occur and the typical magnitude of the current anomaly there (about $0.2 \mathrm{~m} \mathrm{~s}^{-1}$ ), the 3-4-months delay between salinity variability and DMI/ONI evolution can be simply observed as the advective timescale of the salinity front through the central IO. Because the nIOD events in 2010 and 
2016 are both strong, significantly positive salinity anomalies first appear in 2010 autumn and 2016 autumn and last until the following spring. Due to stronger La Niña event in 2010 than 2016, the high salinity anomalies reach the maximum before La Niña recession, so they reach the maximum in January. While in 2017, La Niña recession quickly returns to normal, so the salinity anomalies first decrease and then increase again due to the influence of wind fields, ocean currents, etc. Thus, the anomaly maximum value is in March.

\subsection{Salinity budget analyses of two extremely high salinity events}

From the previous analyses, under the influence of different intensities of nIOD and La Niña events, the salinity anomalies and the related processes during 10A11S and $16 \mathrm{~A} 17 \mathrm{~S}$ are quite different in the tropical central IO. Extremely high salinity anomalies may be related to surface buoyancy fluxes and ocean dynamic processes. To further understand the mechanisms associated with the salinity anomaly variations, we carry out the salinity budget analyses to discuss the main processes contributing to the salinity variability. The salinity budget using datasets with uncertainties from different sources has a large residual term. Therefore, we only provide qualitative analysis to understand the relative contributions of the horizontal advection, vertical entrainment and FWF during 10A11S and 16A17S.

From the previous analyses, we can conclude that there are obviously high salinity anomalies in the tropical central IO during 10A11S and 16A17S. Figure 13 shows the salinity variation tendency and main processes during 10A11S and 16A17S. The value of each term in the salinity budget equation is different in different periods. Some months of these items are larger in former event and other months are larger in latter event. During 10A11S (Figures 13a-c), Salinity increases first, then gradually decreases from December, and finally increases again. At the same time, horizontal advection plus vertical entrainment, which represent ocean dynamic processes ( $\mathrm{S}-\mathrm{adv}$ term in Figure 13a) are positive first, then negative and finally positive. It can be found that $\mathrm{S}-\mathrm{adv}$ term is the largest term even if the residual item is sometimes large, so it is the main factor for the salinity variations for the periods. There is a larger 
positive advection term in September-October 2010 and the advection effects result in the salinity to increase faster. In early 2011, the advection term becomes negative, indicating that it has an inhibitory effect on the increase in salinity, so the salinity shows a trend of gradual decrease. Later, due to smaller positive advection, the salinity increased again. Among them, these variations are mainly caused by zonal advection, especially the abnormal changes of the zonal currents. During 16A17S (Figures $13 \mathrm{~d}-\mathrm{e})$, the salinity changes are very small in the early stage and become large in the later period. The S-adv term changes are the same. Thus, the advection plays a major role in the salinity variations and there are larger values in March-May. In general, advection promotes the increase of salinity, especially the zonal advection.

The FWF is all negative, indicating that it has a negative effect on the salinity variations. The influence in 2010 autumn and 2017 spring is more significant but other periods have a little effect on salinity. In the early stage of the event, the S-adv item in 2010 was greater than 2016. But the S-adv term in 2017 spring is much stronger than that in 2011 spring. In early 2011, the S-adv term is strong negative, and then weak positive. While in early 2017 , the S-adv term changes from small to large. Thus, the high salinity anomalies are caused by the mutual effects of the advection term and the FWF term, but the contribution of the advection term is greater.

In addition, the contributions of the vertical entrainment item are also more obvious and it's larger in 2011 than 2017 (S-advz term in Figure 13b and 13e). Sun et al. (2019) suggested that Rossby waves would propagate westward to the southeastern TIO during IOD events. The downwelling Rossby waves are associated with the negative wind stress curls anomalies in the southeastern TIO during pIOD (Xie et al., 2002, 2009; Yu and Rienecker, 1999; Yu et al., 2005; Zhang et al., 2018), whereas the upwelling Rossby waves take place during nIOD. During the nIOD events, the positive wind stress curls anomalies force cyclonic current anomalies. As 2010 and 2016 are nIOD years and La Niña in 2010 is stronger than 2016, there are stronger upwelling Rossby waves in 2011 than 2017, which make the thermocline shallow. When the thermocline shoals, strengthened Ekman upwelling more easily brings the high salinity and cold water into the upper layer, resulting in a decrease of local 
precipitation. The processes are beneficial for the enhancement of the positive salinity anomalies, so vertical entrainment caused by an anomalous cyclonic gyre maintains high salinity anomalies during the decay phases of the nIOD and La Niña events.

Therefore, Ocean horizontal advection is the main factor of high salinity anomaly variations during 10A11S and 16A17S. The entrainment effects in 2011 are more significant than that in 2017 and the FWF has a negative and small effect on positive salinity anomalies for two events. The mutual effects of horizontal advection, FWF and vertical entrainment together lead to extremely high salinity anomalies in the tropical central IO for two periods.

\section{Summary and Discussion}

Based on 2007-2018 Argo products and various satellite and reanalysis data, there are significantly high salinity anomalies in the tropical central IO during 10A11S and 16A17S. The study provides a detailed description of spatial characteristics of high salinity anomalies and the underlying formation mechanisms. Salinity budget equation is performed to examine the role of surface buoyancy fluxes and ocean dynamic processes.

Surface buoyancy fluxes and ocean dynamic processes are factors affecting the high salinity anomalies for these two periods. The results show that the salinity anomalies in 2010 autumn and 2017 spring are stronger than 2016 autumn and 2011 spring. But at the same time, the precipitation in the first two periods is also larger than that in the latter two periods. The FWF changes and salinity anomaly variations are inconsistent, so the impact of FWF has a small and negative contribution to the high salinity anomalies for two periods. The analyses indicate that the high salinity anomalies cannot be explained directly by the changes in regional air-sea freshwater exchanges.

The co-occurrence of nIOD and La Niña in 2010 and 2016 is the main reason for the occurrence of high salinity anomalies. The strong eastward currents caused by nIOD and La Niña during September-December in 2010 and 2016 make high salinity water transport eastward, triggering positively high salinity anomalies in the eastern 
TIO. Additionally, during January-May in 2011 and 2017, which are the decay phases of nIOD and La Niña, the westward currents transport the high salinity water of the eastern IO westward, resulting in high salinity anomalies in the central IO. As La Niña event is much stronger in 2010 than in 2016, the high salinity anomalies at the end of 2010 appear earlier and are stronger than 2016. Meanwhile, the decline of the former lasts longer, so the salinity anomalies are gradually weakened in early 2011 while the salinity anomalies decrease and then increase in early 2017. Therefore, the two-period maximum salinity anomalies occur at different months, which are in January 2011 and in March 2017, respectively. And the salinity anomalies from March to May in 2017 are more significant than that in 2011. On the other hand, when the nIOD and La Niña events happen, the upwelling Rossby waves caused by cyclonic wind stress curls lead to more cold and salty water entrained into the upper layer, causing the salinity to increase. Due to the La Niña intensity in 2010 is stronger than in 2016, so the entrainment effects in 2011 are stronger than that in 2017. These foregoing results can be summarized by the sketch shown in Figure 14.

The results of the analyses in the study also verify the view that the interannual variations of salinity in the TIO are mainly affected by IOD events. When a nIOD event occurs, positive salinity anomalies caused by westerlies will occur at the end of the year and the beginning of the next year. Depending on the intensities of the occurrence of La Niña, positive salinity anomalies of different intensities will occur; When a pIOD event occurs, the situation is the opposite and negative salinity anomalies of different intensities will occur according to the intensities of the occurrence of El Niño. Therefore, nIOD in 2010 and pIOD in 2011 result in positive salinity anomalies during 10A11S and negative salinity anomalies from 2011 autumn to 2012 spring, respectively. pIOD in 2015 and nIOD in 2016 result in negative salinity anomalies during $15 \mathrm{~A} 16 \mathrm{~S}$ and positive salinity anomalies during 16A17S, respectively. Between the two periods of positive salinity anomalies (i.e. 2012-2016), no strong pIOD events occur, so the salinity has been in negative anomalies or very weak positive anomalies, that is, 2012-2016 is a period of freshening. However, why there are no strong nIOD events during the periods? It may be related to the factors 
such as the climate mode indexes or interdecadal oscillation. This is beyond the scope of the study and left for further research.

In addition, through the quantitative analyses of the salinity budget equation, the advection term is positive and maximum at the end of 2010, then becomes negative and gradually weakens. During $16 \mathrm{~A} 17 \mathrm{~S}$, the advection term is relatively small, and strong positive advection doesn't appear until the spring of 2017. The FWF has a small and negative influence on salinity anomalies. Thus, we further conclude that ocean advection is the main factor of positive salinity anomalies in the tropical central IO. The positive salinity anomalies at the end of 2010 and 2016 are mainly due to the positive zonal advection anomalies. The decrease in salinity anomalies in early 2011 is mainly caused by negative zonal current anomalies and the salinity anomalies in early 2017 first decrease and then increase. They are similar to the results of the previous ocean dynamic analyses. The upwelling generated by vertical entrainment under the influence of nIOD and La Niña also has a certain impact on salinity and the item has a greater impact in 2011 than in 2017. As a result, the mutual effects of horizontal advection, FWF and vertical entrainment together lead to extremely high salinity anomalies in the tropical central IO during 10A11S and 16A17S.

According to the salinity budget equation, in addition to the horizontal advection term, the FWF term and the vertical entrainment term, there is one residual term $\varepsilon$. For the residual term of the salinity budget, the main reason affecting the residual term is that the data are from different sources. There is no dynamical balance among different sources to keep a closed salinity budget. Various centers reconstruct the observations from different sources using different methods, thus cause various errors. The item generally includes some nonlinear terms such as horizontal and vertical mixing disturbance, turbulent diffusion, and the accumulation of errors from the other terms and so on, but these items are relatively complex. Here we only give the qualitative analyses to understand the salinity anomalies. We need to obtain higher-resolution data and improve the methods of computing all terms that contribute to the salinity anomalies.

In short, due to the similar intensities of nIOD events in 2010 and 2016, 
obviously positive salinity anomalies appear in the tropical central IO during 10A11S and 16A17S. However, due to the significant difference in the intensities of the La Niña events, the intensities of positive salinity anomalies for two periods are significantly different. The co-occurrence of nIOD and strong La Niña in 2010 lead to stronger positive zonal advection anomaly firstly and next negative zonal advection anomaly, thus the negative contributions of zonal advection mainly lead to an abnormal decrease in salinity during recession phases. The co-occurrence of nIOD and weak La Niña in 2016 causes positive zonal advection anomaly firstly and next negative zonal advection anomaly, and then positive zonal advection anomaly which mainly result in extremely higher salinity anomalies in 2017 spring. The salinity anomalies at the end of 2010 are stronger than that of 2016, and in 2017 spring are stronger than that in 2011. Our results highlight the important role of the oceanic dynamics in the salinity variability in the TIO. Given the known implications of salinity anomalies on the upper-ocean stratification in the central-eastern TIO and their potential impacts on air-sea interactions and climate variability there, the study provides some new perspectives on the interannual variability of salinity in the TIO.

\section{Acknowledgements}

This study was supported by the Second Tibetan Plateau Scientific Expedition and Research (STEP) program (Grant no. 2019QZKK0102), the Strategic Priority Research Program of Chinese Academy of Sciences (Grant No. XDA20060500), the Open Project Program of State Key Laboratory of Tropical Oceanography (LTOZZ2102), the National Natural Science foundation of China (42176026) and the Independent Research Project Program of State Key Laboratory of Tropical Oceanography (LTOZZ2101).

\section{Data Availability Statement}

The gridded monthly Argo data were downloaded from http://apdrc.soest.hawaii.edu/erddap/griddap/hawaii_soest_4daf_fed7_948a.html. The ECMWF ORAS5 reanalysis data were retrieved from 
http://apdrc.soest.hawaii.edu/erddap/griddap/hawaii_soest_3bf3_9d89_5708.html.

754 The SMAP salinity data were obtained from

755 http://apdrc.soest.hawaii.edu/erddap/griddap/hawaii_soest_0550_cd5c_d5bd.html.

756 The SODA salinity data were downloaded from

757 http://apdrc.soest.hawaii.edu/erddap/griddap/hawaii_soest_bb48_93c2_a711.html.

758 The SMOS salinity data were downloaded from https://www.catds.fr/sipad/. The

759 GPCP monthly precipitation data were available at

760 http://apdrc.soest.hawaii.edu/erddap/griddap/hawaii_soest_2d6e_67ad_91d2.html.

761 The OA Flux monthly evaporation data were available at 762 http://apdrc.soest.hawaii.edu/erddap/griddap/hawaii_soest_6b5a_df06_3eeb.html. The 763 ERSSTv5 SST analysis data were obtained from 764 http://apdrc.soest.hawaii.edu/erddap/griddap/hawaii_soest_31a3_72d5_401e.html.

765 The reanalysis data NCEP monthly pressure zonal wind and meridional wind were 766 extracted from 767 http://apdrc.soest.hawaii.edu/erddap/griddap/hawaii_soest_9bf0_875c_a184.html and http://apdrc.soest.hawaii.edu/erddap/griddap/hawaii_soest_3c0a_cfec_e866.html,

769 respectively. The OFES model data were retrieved from 770 http://apdrc.soest.hawaii.edu/erddap/griddap/hawaii_soest_6c0d_24b8_6937.html for 771 zonal velocity and 772 http://apdrc.soest.hawaii.edu/erddap/griddap/hawaii_soest_c66b_2477_13c0.html for 773 meridional velocity. All data needed to evaluate the conclusions in the paper are 774 present in the paper and/or the Supplementary Materials. Additional data related to 775 this paper may be requested from the authors.

\section{References}

Adler, R. F., Huffman, G. J., Chang, A., Ferraro, R., Xie, P.-P., Janowiak, J., Rudolf, B., Schneider, U., Curtis, S., Bolvin, D., Gruber, A., Susskind, J., Arkin, P. and Nelkin, E. (2003) The version-2 Global Precipitation Climatology Project (GPCP) monthly precipitation analysis (1979-present). Journal of Hydrometeorology, 4, 1147-1167. https://doi.org/10.1175/1525-7541(2003)004\%3C1147:TVGPCP\%3E2.0.CO;2.

Bhavani, T. S. D., Chowdary, J. S., Bharathi, G., Srinivas, G., Prasad, K. V. S. R., Deshpande, 
A., Parekh, A. and Gnanaseelan, C. (2017) Response of the tropical Indian Ocean SST to decay phase of La Niña and associated processes. Dynamics of Atmospheres and Oceans, 80, 110-123. https://doi.org/10.1016/j.dynatmoce.2017.10.005.

Burns, J. M. and Subrahmanyam, B. (2016) Variability of the Seychelles-Chagos Thermocline Ridge dynamics in connection with ENSO and Indian Ocean Dipole. IEEE Geoscience and Remote Sensing Letters, 13, 2019-2023. https://doi.org/10.1109/LGRS.2016.2621353.

Cai, W., Pan, A., Roemmich, D., Cowan, T. and Guo, X. (2009) Argo profiles a rare occurrence of three consecutive positive Indian Ocean Dipole events, 2006-2008. Geophysical Research Letters, 36, L08701. https://doi.org/10.1029/2008GL037038.

Clarke, A. J. and Liu, X. (1994) Interannual sea level in the northern and eastern Indian Ocean. Journal of Physical Oceanography, 24, 1224-1235. https://doi.org/10.1175/1520-0485(1994)024<1224:ISLITN>2.0.CO;2.

Delcroix, T. and Hénin, C. (1991) Seasonal and interannual variations of sea surface salinity in the tropical Pacific Ocean. Journal of Geophysical Research, 96, 22, 135-22, 150. https://doi.org/10.1029/91JC02124.

Durack, P. J. and Wijffels, S. E. (2010) Fifty-year trends in global ocean salinities and their relationship to broad-scale warming. Journal of Climate, 23, 4342-4362. https://doi.org/10.1175/2010JCLI3377.1.

Durack, P. J., Wijffels, S. E. and Matear, R. J. (2012) Ocean salinities reveal strong global water cycle intensification during 1950-2000. Science, 336, 455-458. https://doi.org/10.1126/science.1212222.

Du, Y. and Zhang, Y. H. (2015) Satellite and Argo observed surface salinity variations in the topical Indian Ocean and their association with the Indian Ocean Dipole Mode. Journal of Climate, 28, 695-713. https://doi.org/10.1175/JCLI-D-14-00435.1.

Du, Y., Xie, S.-P., Huang, G. and Hu, K. (2009) Role of air-sea interaction in the long persistence of El Niño-induced North Indian Ocean warming. Journal of Climate, 22, 2023-2038. https://doi.org/10.1175/2008jcli2590.1.

Feng, M., Meyers, G., Pearce, A. and Wijffels, S. (2003) Annual and interannual variations of the Leeuwin Current at $32^{\circ} \mathrm{S}$. Journal of Geophysical Research, 108, 3355. https://doi.org/10.1029/2002JC001763.

Feng, M., McPhaden, M. J. and Lee, T. (2010) Decadal variability of the Pacific subtropical cells and their influence on the southeast Indian Ocean. Geophysical Research Letters, 37, L09606. https://doi.org/10.1029/2010GL042796.

Font, J., Camps, A., Borges, A., Martín-Neira, M., Boutin, J., Reul, N., H. Kerr, Y., Hahne, A. and Mecklenburg, S. (2010) SMOS: the challenging sea surface salinity measurement from space. Proceedings of the IEEE, 98, 649-665. https://doi.org/10.1109/JPROC.2009.2033096.

Fore, A., Yueh, S., Tanh, W. and Hayashi, A. (2020) JPL SMAP Ocean Surface Salinity 
Products [Level 2B, Level 3 Running 8-day, Level 3 Monthly], Version 5.0 validated release. Jet Propulsion Laboratory, Pasadena, CA, USA.

Gao, S., Qu, T. and Nie, X. (2014) Mixed layer salinity budget in the tropical Pacific Ocean estimated by a global GCM. Journal of Geophysical Research: Oceans, 119, 8255-8270. https://doi.org/10.1002/2014JC010336.

Gnanaseelan, C., Deshpande, A. and McPhaden, M. J. (2012) Impact of Indian Ocean Dipole and El Niño/Southern Oscillation wind-forcing on the Wyrtki jets. Journal of Geophysical Research, 117, C08005. https://doi.org/10.1029/2012JC007918.

Gould, J., Roemmich, D., Wijffels, S., Freeland, H., Ignaszewsky, M., Xu, J., Pouliquen, S., Desaubies, Y., Send, U., Radjalrishnan, K., Takeuchi, K., Kim, K., Danchenkov, M., Sutton, P., King, B., Owens, B. and Riser, S. (2004) Argo profiling floats bring new era of in situ ocean observations. Eos, Transactions of the American Geophysical Union, 85, 185-191. https://doi.org/10.1029/2004EO190002.

Grunseich, G., Subrahmanyam, B. and Wang, B. (2013) The Madden-Julian oscillation detected in Aquarius salinity observations. Geophysical Research Letters, 40, 5461-5466. https://doi.org/10.1002/2013GL058173.

Grunseich, G., Subrahmanyam, B., Murty, V. S. N. and Giese, B. S. (2011) Sea surface salinity variability during the Indian Ocean Dipole and ENSO events in the tropical Indian Ocean. Journal of Geophysical Research, 116, C11013. https://doi.org/10.1029/2011JC007456.

Guan, B., Lee, T., Halkides, D. J. and Waliser, D. E. (2014) Aquarius surface salinity and the Madden-Julian Oscillation: The role of salinity in surface layer density and potential energy. Geophysical Research Letters, 41, 2858-2869. https://doi.org/10.1002/2014GL059704.

Hasson, A., Delcroix, T., Boutin, J., Dussin, R. and Ballabrera-Poy, J. (2014) Analyzing the 2010-2011 La Niña signature in the tropical Pacific sea surface salinity using in situ data, SMOS observations, and a numerical simulation. Journal of Geophysical Research: Oceans, 119, 3855-3867. https://doi.org/10.1002/2013JC009388.

Hasson, A. E. A., Delcroix, T. and Dussin, R. (2013) An assessment of the mixed layer salinity budget in the tropical Pacific Ocean. Observations and modelling (1990-2009). Ocean Dynamics, 63, 179-194. https://doi.org/10.1007/s10236-013-0596-2.

Hong, C.-C., Lu, M.-M. and Kanamitsu, M. (2008) Temporal and spatial characteristics of positive and negative Indian Ocean dipole with and without ENSO, Journal of Geophysical Research, 113, D08107. https://doi.org/10.1029/2007JD009151.

Horii, T., Ueki, I., Ando, K., Hasegawa, T., Mizuno, K. and Seiki, A. (2016) Impact of intraseasonal salinity variations on sea surface temperature in the eastern equatorial Indian Ocean. Journal of Oceanography, 72, 313-326. https://doi.org/10.1007/s10872-015-0337-x.

Huffman, G. J., Adler, R. F., Bolvin, D. T. and Gu, G. (2009) Improving the global 
precipitation record: GPCP version 2.1. Geophysical Research Letters, 36, L17808. https://doi.org/10.1029/2009GL040000.

Jensen, T. G. (2003) Cross-equatorial pathways of salt and tracers from the northern Indian Ocean: Modelling results. Deep-Sea Research Part II, 50, 2111-2127. https://doi.org/10.1016/S0967-0645(03)00048-1.

Kido, S. and Tozuka, T. (2017) Salinity Variability Associated with the Positive Indian Ocean Dipole and Its Impact on the Upper Ocean Temperature. Journal of Climate, 30, 7885-7907. https://doi.org/10.1175/JCLI-D-17-0133.1.

Kido, S., Tozuka, T. and Han, W. (2019) Anatomy of salinity anomalies associated with the positive Indian Ocean Dipole. Journal of Geophysical Research: Oceans, 124, 8116-8139. https://doi.org/10.1029/2019JC015163.

Lagerloef, G. S. E. (2002) Introduction to the special section: The role of surface salinity on upper ocean dynamics, air-sea interaction and climate. Journal of Geophysical Research, 107, 8000. https://doi.org/10.1029/2002JC001669.

Li, J., Liang, C., Tang, Y., Liu, X., Lian, T., Shen, Z. and Li, X. (2018) Impacts of the IOD-associated temperature and salinity anomalies on the intermittent equatorial undercurrent anomalies. Climate Dynamics, 51, 1391-1409. https://doi.org/10.1007/s00382-017-3961-x.

Liang, Z., Xie, Q., Zeng, L. and Wang, D. (2018) Role of wind forcing and eddy activity in the intraseasonal variability of the barrier layer in the South China Sea. Ocean Dynamics, 68, 363-375. https://doi.org/10.1007/s10236-018-1137-9.

Martins, M. S. and Stammer, D. (2015) Pacific Ocean surface freshwater variability underneath the double ITCZ as seen by satellite sea surface salinity retrievals. Journal of Geophysical Research: Oceans, 120, 5870-5885. https://doi.org/10.1002/2015JC010895.

Masumoto, Y., Sasaki, H., Kagimoto, T., Komori, N., Ishida, A., Sasai, Y., Miyama, Y., Motoi, T., Mitsudera, N., Takahashi, K., Sakuma, H. and Yamagata, T. (2004) A fifty-year eddy-resolving simulation of the world ocean-Preliminary outcomes of OFES (OGCM for the Earth Simulator). Journal of the Earth Simulator, 1, 35-56. https://www.researchgate.net/publication/242679951.

Mecklenburg, S., Kerr, Y., Font, J. and Hahne, A. (2008) The Soil Moisture and Ocean Salinity (SMOS) mission - an overview. IEEE International Geoscience and Sensing Symposium, 10, IV-938-IV-941. https://doi.org/10.1109/IGARSS.2008.4779878.

Meyers, G. (1996) Variation of Indonesian throughflow and the El Niño-Southern Oscillation. Journal of Geophysical Research, 101, 12, 255-12, 263. https://doi.org/10.1029/95JC03729.

Murtugudde, R., McCreary, J. P. and Busalacchi, A. J. (2000) Oceanic processes associated with anomalous events in the Indian Ocean with relevance to 1997-1998. Journal of Geophysical Research, 105, 3295-3306. https://doi.org/10.1029/1999JC900294.

Nyadjro, E. S. and Subrahmanyam, B. (2014) SMOS salinity mission reveals salinity 
structure of the Indian Ocean Dipole. IEEE Geoscience and Remote Sensing Letters, 11, 1564-1568, https://doi.org/10.1109/LGRS.2014.2301594.

Nyadjro, E. S., Subrahmanyam, B., Murty, V. S. N. and Shriver, J. F. (2012) The role of salinity on the dynamics of the Arabian Sea mini warm pool. Journal of Geophysical Research, 117, C09002. https://doi.org/10.1029/2012JC007978.

Phillips, H. E., Tandon, A., Furue, R., Hood, R., Ummenhofer, C. C., Benthuysen, J. A., Menezes, V., Hu, S., Webber, B., Sanchez-Franks, A., Cherian, D., Shroyer, E., Feng, M., Wijesekera, H., Chatterjee, A., Yu, L., Hermes, J., Murtugudde, R., Tozuka, T., Su, D., Singh, A., Centurioni, L., Prakash, S. and Wiggert, J. (2021) Progress in understanding of Indian Ocean circulation, variability, air-sea exchange, and impacts on $\begin{array}{llll}\text { biogeochemistry. } & \text { Ocean } & \text { Science, } & 17,\end{array}$ https://doi.org/10.5194/os-17-1677-2021.

Qu, T., Gao, S. and Fukumori, I. (2013) Formation of salinity maximum water and its contribution to the overturning circulation in the North Atlantic as revealed by a global general circulation model. Journal of Geophysical Research: Oceans, 118, 1982-1994. https://doi.org/10.1002/jgrc.20152.

Rao, R. R. and Sivakumar, R. (2003) Seasonal variability of sea surface salinity and salt budget of the mixed layer of the north Indian Ocean. Journal of Geophysical Research, 108, 3009. https://doi.org/10.1029/2001JC000907.

Ren, L. and Riser, S. C. (2009) Seasonal salt budget in the northeast Pacific Ocean. Journal of Geophysical Research, 114, C12004. https://doi.org/10.1029/2009JC005307.

Ren, L., Speer, K. and Chassignet, E. P. (2011) The mixed layer salinity budget and sea ice in the Southern Ocean. Journal of Geophysical Research, 116, C08031. https://doi.org/10.1029/2010JC006634.

Reppin, J., Schott, F. A., Fischer, J. and Quadfasel, D. (1999) Equatorial currents and transports in the upper central Indian Ocean: Annual cycle and interannual variability. Journal of Geophysical Research, 104, 15495-15514. https://doi.org/10.1029/1999JC900093.

Riser, S. C., Ren, L. and Wong, A. (2008) Salinity in Argo: A modern view of a changing ocean. Oceanography, 21, 56-67. https://doi.org/10.5670/oceanog.2008.67.

Roemmich, D. and the Argo Steering Team. (2009) Argo: The challenge of continuing 10 years of progress. Oceanography, 22, 46-55. https://doi.org/10.5670/oceanog.2009.65.

Roemmich, D. and Owens, W. B. (2000) The Argo project: Global ocean observations for understanding and prediction of climate variability. Oceanography, 13, 45-50. https://doi.org/10.5670/oceanog.2000.33.

Saji, N. H., Goswami, B. N., Vinayachandran, P. N. and Yamagata, T. (1999) A dipole mode in the tropical Indian Ocean. Nature, 401, 360-363. https://www.nature.com/articles/43854.

Saji, N. H. and Yamagata, T. (2003) Possible impacts of Indian Ocean Dipole mode events on global climate. CLIMATE

RESEARCH,

25 , 151-169. 
https://www.jstor.org/stable/24868393.

Sasaki, Y., Ishida, A., Yamanaka, Y. and Sasaki, H. (2004) Chlorofluorocarbons in a global ocean eddy-resolving OGCM: Pathway and formation of Antarctic Bottom Water. Geophysical Research Letters, 31, L12305. https://doi.org/10.1029/2004GL019895.

Schiller, A., Mikolajewicz, U. and Voss, R. (1997) The stability of the North Atlantic thermohaline circulation in a coupled ocean-atmosphere general circulation model. Climate Dynamics, 13, 325-347. https://doi.org/10.1007/s003820050169.

Schmitt, R. N. W. (2008) Salinity and the global water cycle. Oceanography, 21, 12-19. https://doi.org/10.5670/oceanog.2008.63.

Schmitt, R. W. and Blair, A. (2015) A river of salt. Oceanography, 28, 40-45. https://doi.org/10.5670/oceanog.2015.04.

Schott, F. A., Xie, S.-P. and McCreary, J. P. (2009) Indian Ocean circulation and climate variability. Reviews of Geophysical, $\quad 47, \quad$ RG1002. https://doi.org/10.1029/2007RG000245.

Sharma, R., Agarwal, N., Momin, I. M., Basu, S. and Agarwal, V. K. (2010) Simulated Sea Surface Salinity Variability in the Tropical Indian Ocean. Journal of Climate, 23, 6542-6554. https://doi.org/10.1175/2010JCLI3721.1.

Sharma, S., Kumari, A., Navajyoth, M. P., Kumar, P. and Saharwardi, M. S. (2020) Impact of air-sea interaction during two contrasting monsoon seasons. Theoretical and Applied Climatology, 141, 1645-1659. https://doi.org/10.1007/s00704-020-03300-6.

Simon, B., Rahman, S. H. and Joshi, P. C. (2006) Conditions leading to the onset of the Indian monsoon: A satellite perspective. Meteorology and Atmospheric Physics, 93, 201-210. https://doi.org/10.1007/s00703-005-0155-6.

Skliris, N., Marsh, R., Josey, S. A., Good, S. A., Liu, C. and Allan, R. P. (2014) Salinity changes in the World Ocean since 1950 in relation to changing surface freshwater fluxes. Climate Dynamics, 43, 709-736. https://doi.org/10.1007/s00382-014-2131-7.

Stammer, D. (1997) Global characteristics of ocean variability estimated from regional TOPEX/POSEIDON altimeter measurements. Journal of physical oceanography, 27, 1743-1769. https://doi.org/10.1175/1520-0485(1997)027<1743:GCOOVE>2.0.CO;2.

Stuecker, M. F., Timmermann, A., Jin, F.-F., Chikamoto, Y., Zhang, W., Wittenberg, A. T., Widiasih, E. and Zhao, S. (2017) Revisiting ENSO/Indian Ocean Dipole phase relationships. Geophysical Research Letters, 44, 2481-2492. https://doi.org/10.1002/2016GL072308.

Subrahmanyam, B., Murty, V. S. N. and Heffner, D. M. (2011) Sea Surface Salinity Variability in the Tropical Indian Ocean. Remote Sensing of Environment, 115, 944-956. https://doi.org/10.1016/j.rse.2010.12.004.

Sun, Q., Du, Y., Zhang, Y., Feng, M., Chowdary, J. S., Chi, J., Qiu, S. and Yu, W. (2019) Evolution of sea surface salinity anomalies in the southwestern tropical Indian Ocean during 2010-2011 influenced by a negative IOD event. Journal of Geophysical Research: 
Oceans, 124, 3428-3445. https://doi.org/10.1029/2018JC014580.

Sun, S., Lan, J., Fang, Y., Tana and Gao, X. (2015) A triggering mechanism for the Indian Ocean Dipoles independent of ENSO. Journal of Climate, 28, 5063-5076. https://journals.ametsoc.org/view/journals/clim/28/13/jcli-d-14-00580.1.xml.

Thompson, B., Gnanaseelan, C. and Salvekar, P. S. (2006) Variability in the Indian Ocean circulation and salinity and its impact on SST anomalies during dipole events. Journal of Marine Research, 64, 853-880. https://doi.org/10.1357/002224006779698350.

Tozuka, T., Yokoi, T. and Yamagata, T. (2010) A modeling study of interannual variations of the seychelles dome. Journal of Geophysical Research, 115, $\mathrm{C} 04005$. https://doi.org/10.1029/2009JC005547.

Vinayachandran, P. N. and Nanjundiah, R. S. (2009) Indian Ocean sea surface salinity variations in a coupled model. Climate Dynamics, 33, 245-263. https://doi.org/10.1007/s00382-008-0511-6.

Wang, B., Wu, R. and Li, T. (2003) Atmosphere-warm ocean interaction and its impacts on Asian-Australian monsoon variation. Journal of Climate, 16, 1195-1211. https://doi.org/10.1175/1520-0442(2003)16\%3C1195:AOIAII\%3E2.0.CO;2.

Wijffels, S. and Meyers, G. (2004) An intersection of oceanic waveguides: Variability in the Indonesian Throughflow region. Journal of Physical Oceanography, 34, 1232-1253. https://doi.org/10.1175/1520-0485(2004)034\%3C1232:AIOOWV\%3E2.0.CO;2.

Williams, P. D., Guilyardi, E., Madec, G., Gualdi, S. and Scoccimarro, E. (2010) The role of mean ocean salinity in climate. Dynamics of Atmospheres and Oceans, 49, 108-123. https://doi.org/10.1016/j.dynatmoce.2009.02.001.

Wyrtki, K. (1973) An equatorial jet in the Indian Ocean. Science, 181, 262-264. https://doi.org/10.1126/science.181.4096.262.

Xie, S.-P., Annamalai, H., Schott, F. A. and McCreary, J. P. (2002) Structure and mechanism of South Indian Ocean climate variability. Journal of Climate, 15, 864-878. https://doi.org/10.1175/1520-0442(2002)0152.0.CO;2.

Xie, S.-P., Hu, K., Hafner, J., Tokinaga, H., Du, Y., Huang, G. and Sampe, T. (2009) Indian Ocean capacitor effect on Indo-western Pacific climate during the summer following El Niño. Journal of Climate, 22, 730-747. https://doi.org/10.1175/2008JCLI2544.1.

Yadav, R. K. and Roxy, M. K. (2019) On the relationship between north India summer monsoon rainfall and east equatorial Indian Ocean warming. Global and Planetary Change, 179, 23-32. https://doi.org/10.1016/j.gloplacha.2019.05.001.

Yokoi, T., Tozuka, T. and Yamagata, T. (2008) Seasonal variation of the Seychelles Dome. Journal of Climate, 21, 3740-3754. https://doi.org/10.1175/2008JCLI1957.1.

Yokoi, T., Tozuka, T. and Yamagata, T. (2012) Seasonal and interannual variations of the SST above the Seychelles Dome. Journal of Climate, 25, 800-814. https://doi.org/10.1175/JCLI-D-10-05001.1.

Yu, L. and Rienecker, M. M. (1999) Mechanisms for the Indian Ocean warming during the 
1997-98 El Niño. Geophysical Research Letters, 26, 735-738. https://doi.org/10.1029/1999GL900072.

Yu, L. and Weller, R. A. (2007) Objectively analyzed air-sea heat fluxes for the global ice-free oceans (1981-2005). American Meteorological Society, 88, 527-540. https://doi.org/10.1175/BAMS-88-4-527.

Yu, W., Xiang, B., Liu, L. and Liu, N. (2005) Understanding the origins of interannual thermocline variations in the tropical Indian Ocean. Geophysical Research Letters, 32, L24706. https://doi.org/10.1029/2005GL024327.

Zeng, L. and Wang, D. (2017) Seasonal variations in the barrier layer in the South China Sea: characteristics, mechanisms and impact of warming. Climate Dynamics, 48, 1911-1930. https://doi.org/10.1007/s00382-016-3182-8.

Zhang, L., Du, Y. and Cai, W. (2018) Low-frequency variability and the unusual Indian Ocean Dipole events in 2015 and 2016. Geophysical Research Letters, 45, 1040-1048. https://doi.org/10.1002/2017GL076003.

Zhang, Y., Du, Y., Jayarathna, W. N. D. S., Sun, Q., Zhang, Y., Yao, F. and Feng, M. (2020) A prolonged high-salinity event in the Northern Arabian Sea during 2014-2017. Journal of Physical Oceanography, 50, 849-865. https://doi.org/10.1175/JPO-D-19-0220.1.

Zhang, Y., Du, Y., Zheng, S., Yang, Y. and Cheng, X. (2013) Impact of Indian Ocean dipole on the salinity budget in the equatorial Indian Ocean. Journal of Geophysical Research: Oceans, 118, 4911-4923. https://doi.org/10.1002/jgrc.20392. 

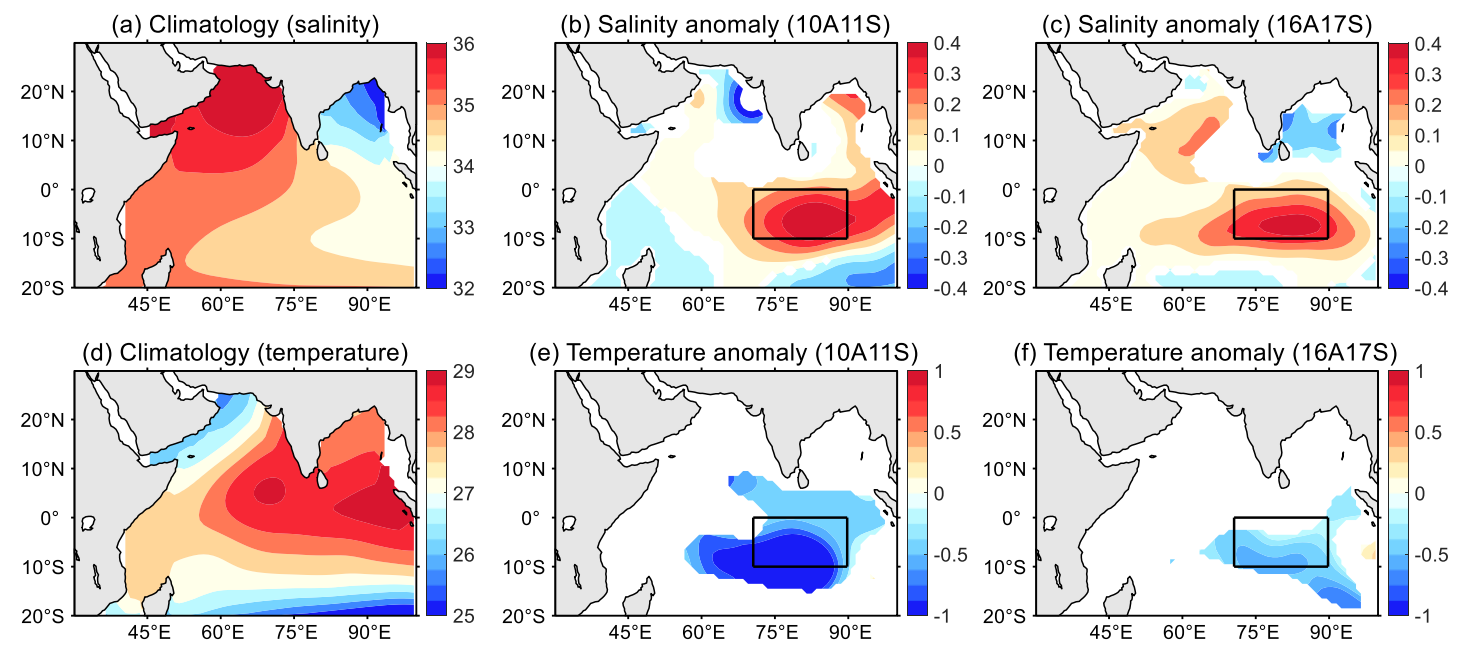

Figure 1. Annual climatological mean spatial distribution of the upper (a) salinity (unit: psu) and (d) temperature (unit: ${ }^{\circ} \mathrm{C}$ ) in the tropical and subtropical IO based on the Argo data from 2007-2018; The spatial distributions of salinity anomaly (unit: psu) in the above areas during (b) 10A11S and (c) 16A17S. (e) and (f) are the same as (b) and (c), but for temperature anomaly (unit: ${ }^{\circ} \mathrm{C}$ ). Only the anomalies exceeding the $95 \%$ confidence level based on a Student's t-test are shown. The black closed boxes in (b) and (c) denote the main area with positive salinity anomalies and in (e) and (f) indicate the position corresponding to the positive salinity anomalies. 


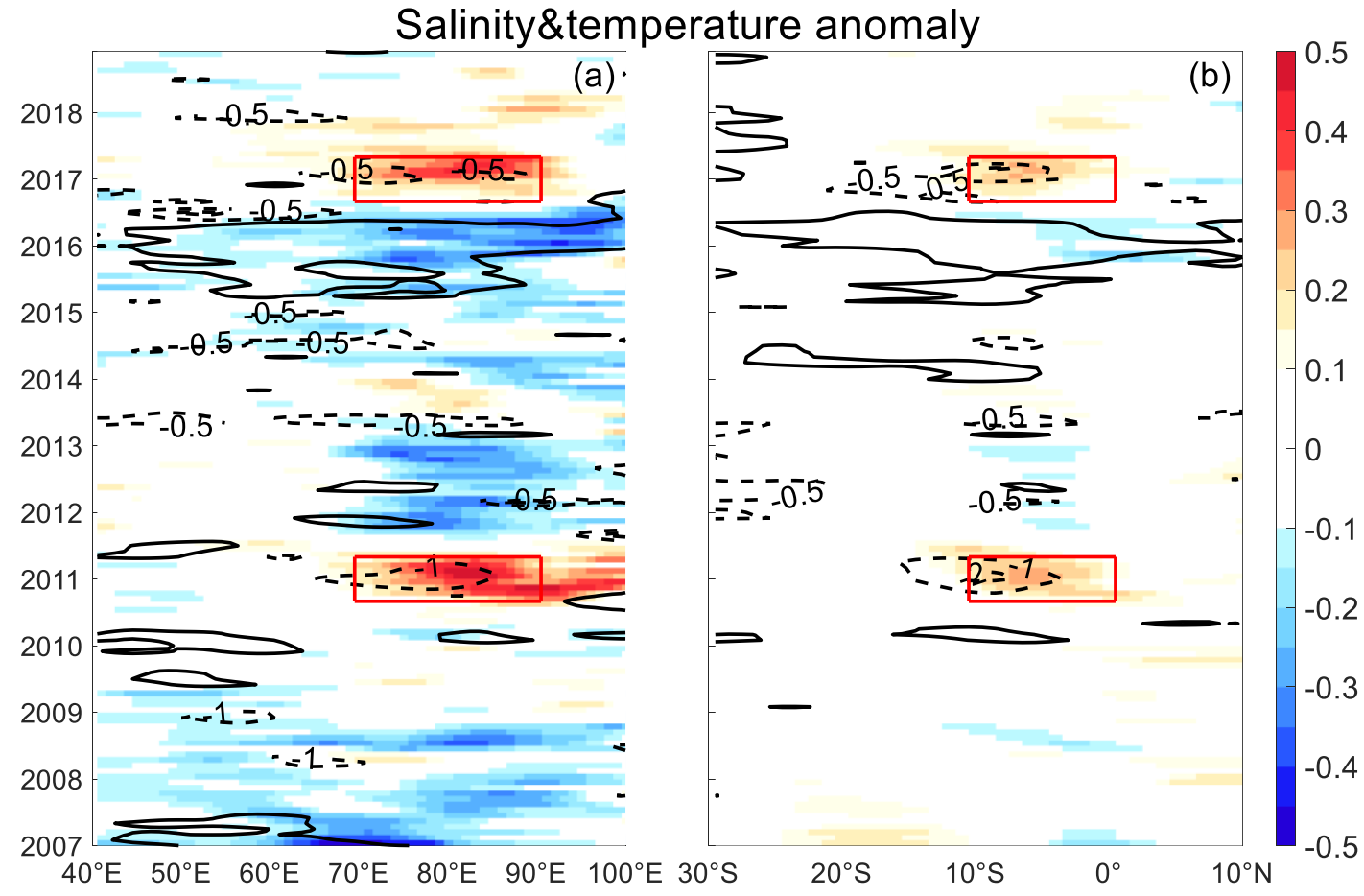

Figure 2. Hovmöller diagrams of salinity anomaly (shading, unit: psu) and temperature anomaly (contours, unit: ${ }^{\circ} \mathrm{C}$ ) along (a) zonal section, averaged meridionally in $10^{\circ} \mathrm{S}-0^{\circ}$ and (b) meridional section, averaged zonally in $70^{\circ} \mathrm{E}-90^{\circ} \mathrm{E}$ based on the Argo data during 2007-2018. The red boxes represent the extremely high salinity anomalies during 10A11S and 16A17S. 

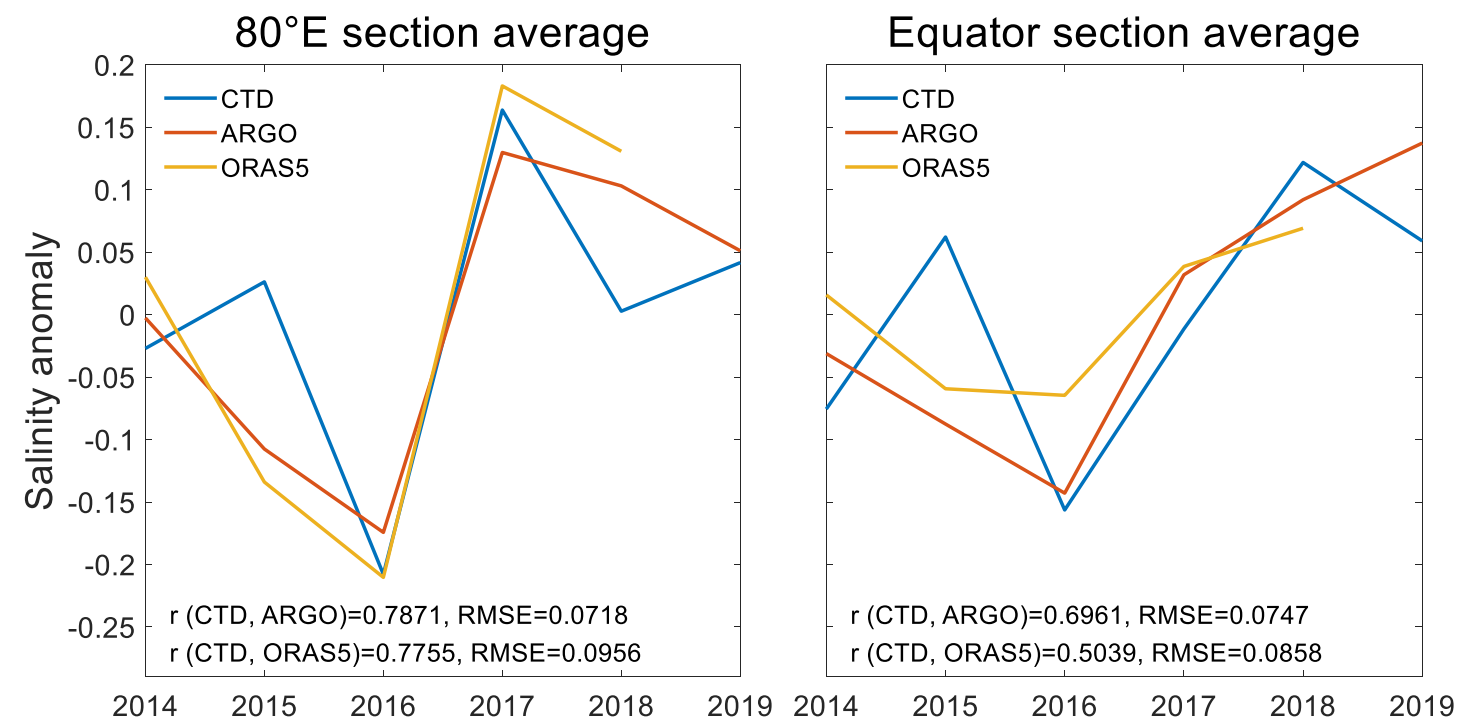

Figure 3. Comparisons between the time series of the CTD (blue), ARGO (red), ECMWF ORAS5 (yellow) salinity anomaly (unit: psu) area-averaged at $80^{\circ} \mathrm{E}$ (left) and equator (right) sections from 2014 to 2019. The correlation coefficients and RMSEs between the time series are estimated for the periods both the data are available. 
Salinity anomaly

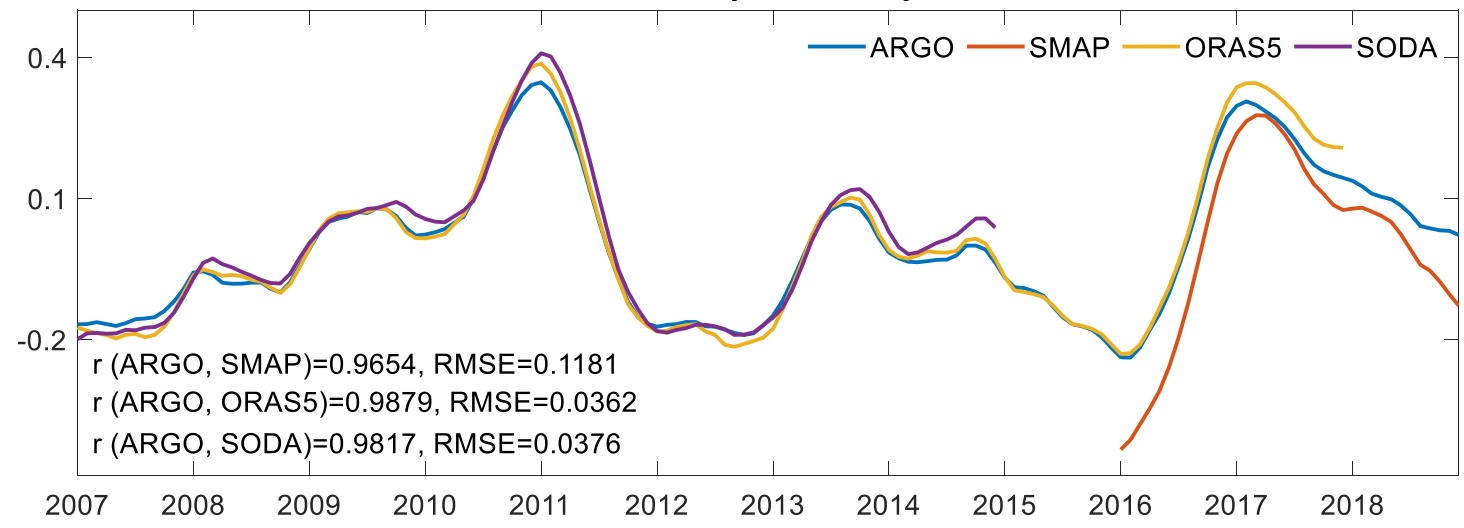

Figure 4. Comparisons between the time series of the ARGO (blue), SMAP (red), ECMWF ORAS5 (yellow) and SODA (purple) salinity anomaly (unit: psu) area-averaged from 2007 to 2018. The correlation coefficients and RMSEs between the time series are estimated for the periods both the data are available. 

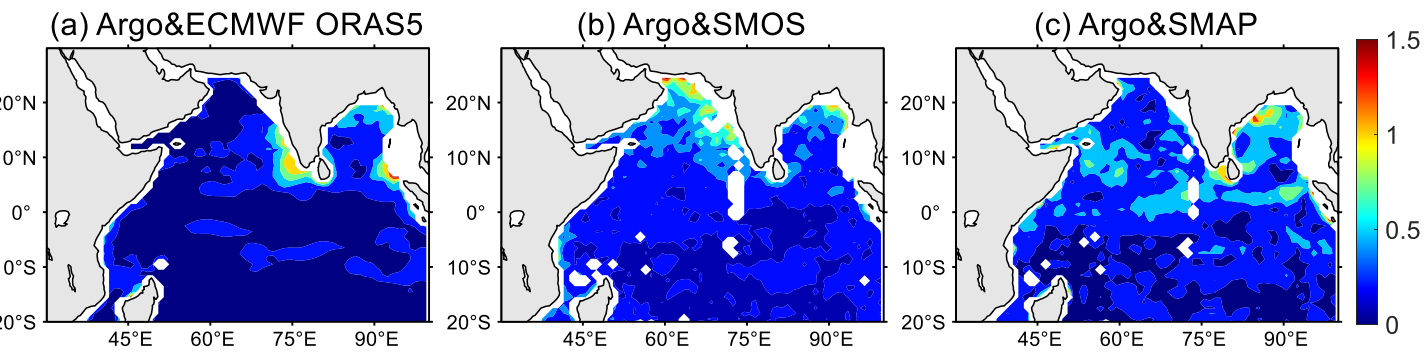

Figure 5. The spatial distributions of salinity RMSEs (a) between Argo and ECMWF ORAS5 data, (b) between Argo and SMOS data, (c) between Argo and SMAP data. 
(a) Salinity\&temperature

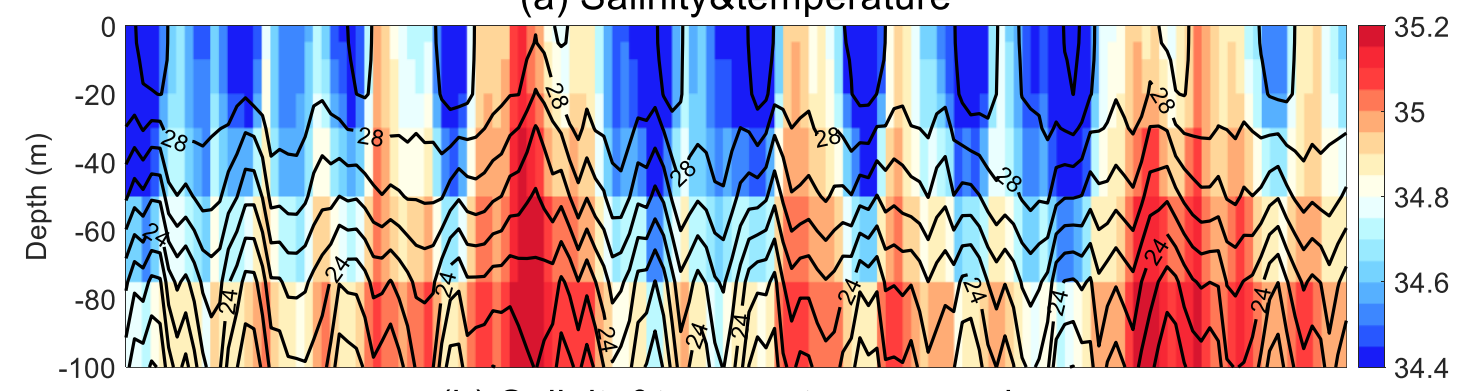

(b) Salinity\&temperature anomaly

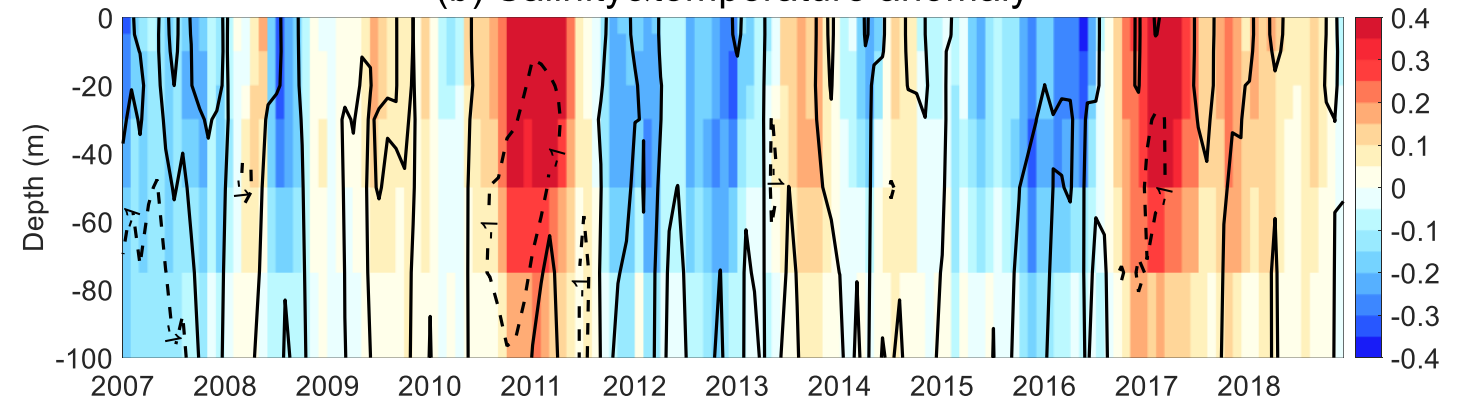

Figure 6. Time-depth distributions of area-averaged (a) salinity (shading) and temperature (contours) and (b) salinity anomaly (shading, unit: psu) and temperature anomaly (contours, unit: ${ }^{\circ} \mathrm{C}$ ) from 2007 to 2018 based on the Argo data. 
(a) 2010 autumn (Sep-Nov)

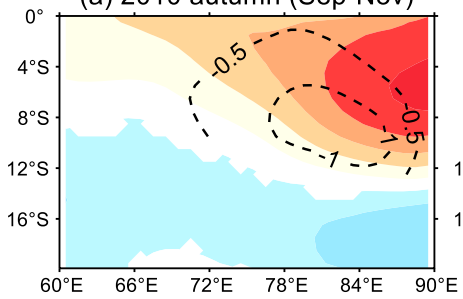

(d) 2016 autumn (Sep-Nov)

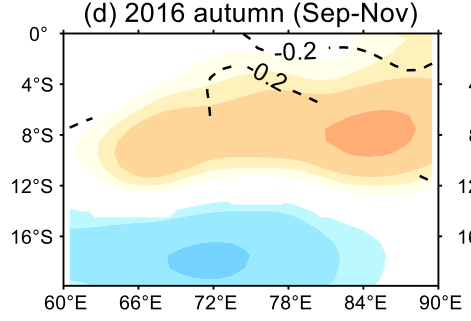

(b) 2010 winter (Dec-Feb)

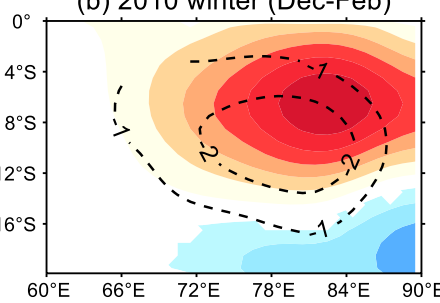

(e) 2016 winter (Dec-Feb)

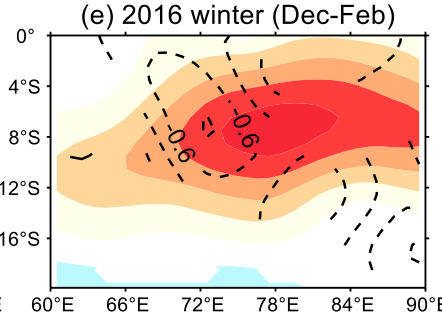

(c) 2011 spring (Mar-May)

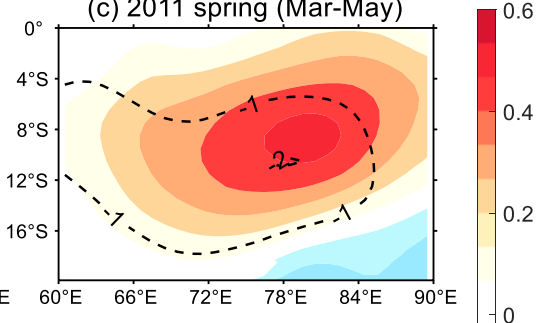

(f) 2017 spring (Mar-May)

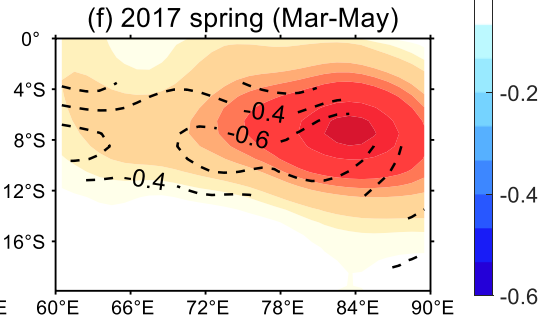

Figure 7. Spatial distributions of three-month moving mean high salinity anomaly (shading, unit: psu) and SSTA (contours, unit: ${ }^{\circ} \mathrm{C}$ ) during (a-c) 10A11S and (d-f) 16A17S based on the Argo data in the main high salinity anomaly area. Only the anomalies exceeding the 95\% confidence level based on a Student's t-test are shown. 


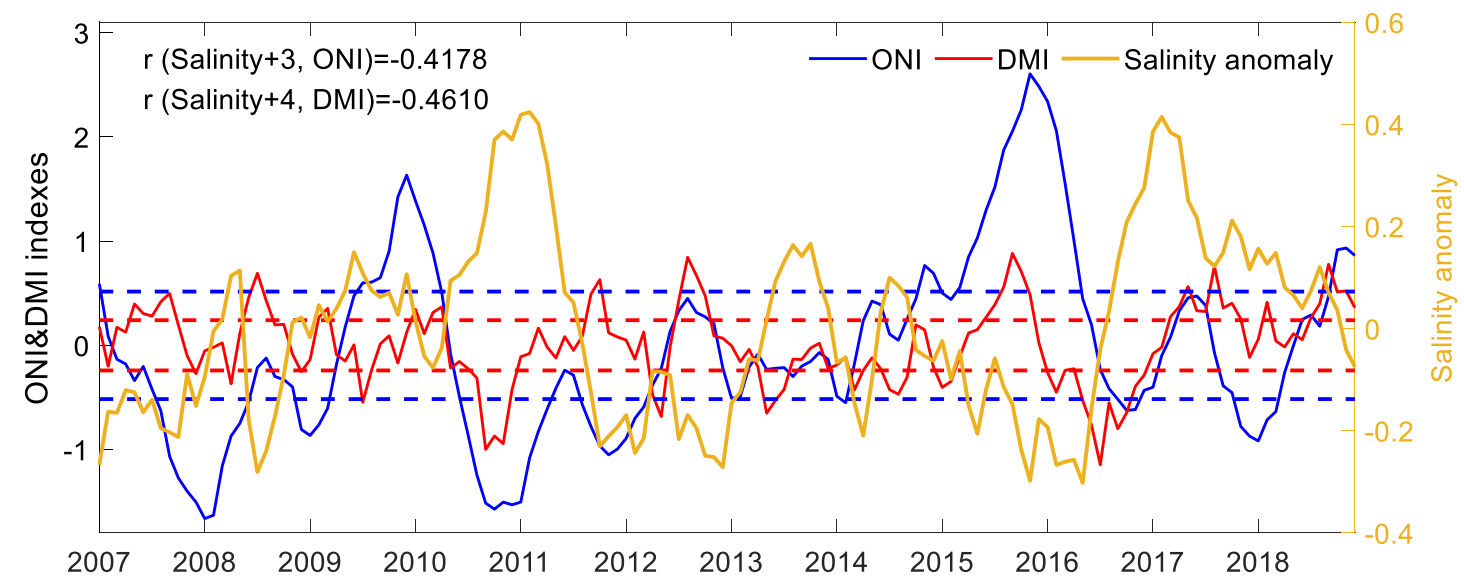

Figure 8. Time series of the ONI (blue curve) and DMI (red curve) indexes (unit: ${ }^{\circ} \mathrm{C}$ ) in 2007-2018. The blue and red dashed lines denote the threshold of \pm 0.5 times the standard deviation for ONI and DMI, respectively. The yellow curve denotes the time series of salinity anomaly (unit: psu) area-averaged in $70^{\circ} \mathrm{E}-90^{\circ} \mathrm{E}, 10^{\circ} \mathrm{S}-0^{\circ}$. 
(a) 2010 autumn (Sep-Nov)

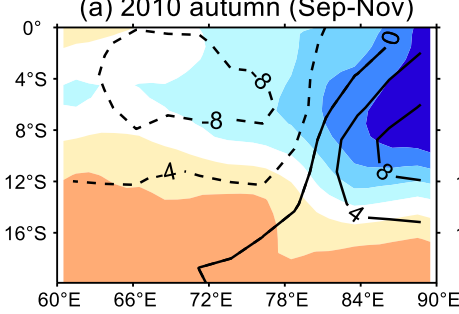

(b) 2010 winter (Dec-Feb)

(c) 2011 spring (Mar-May)
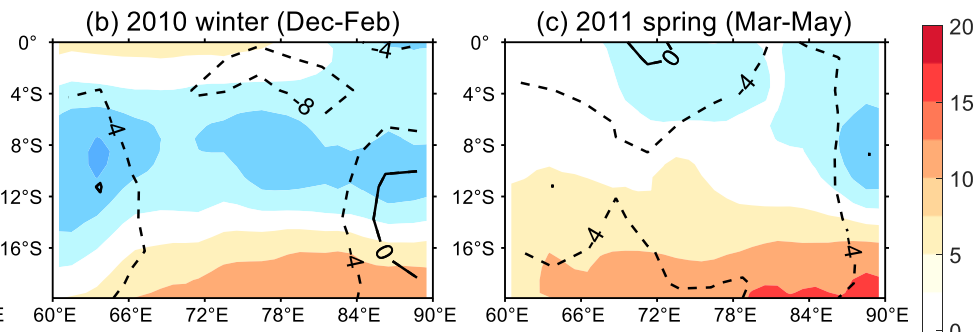

(d) 2016 autumn (Sep-Nov)

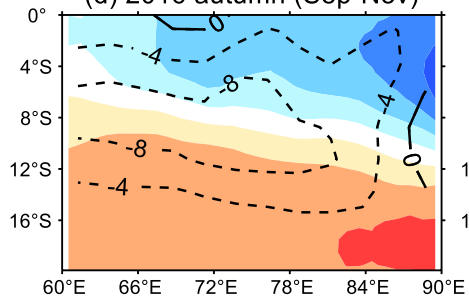

(e) 2016 winter (Dec-Feb)
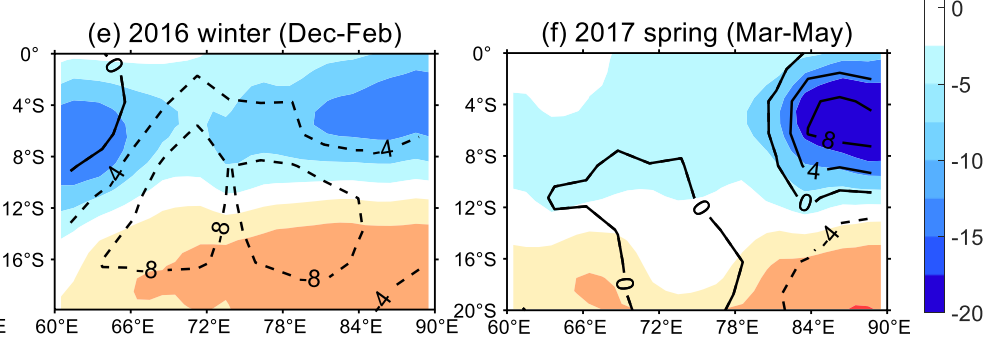

Figure 9. Spatial distributions of cumulative precipitation anomaly (contours, unit: $\mathrm{mm}$ per day) and surface FWF (i.e. evaporation minus precipitation; shading, unit: $\mathrm{mm}$ per day) in three months during (a-c) 10A11S and (d-f) 16A17S. 
(a) Sep 2010

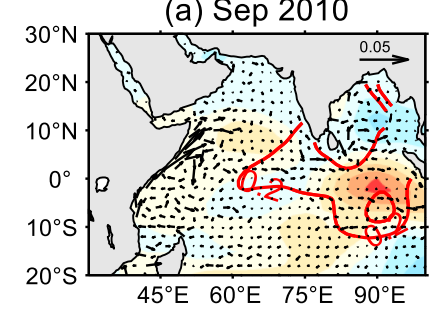

(d) Dec 2010

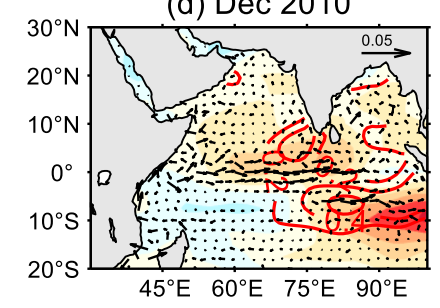

(g) Mar 2011

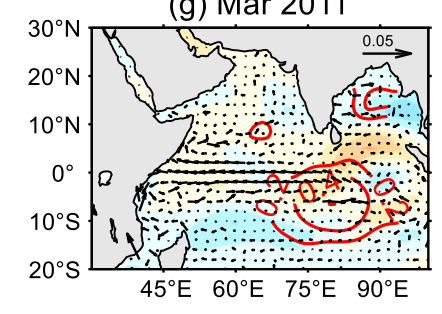

(b) Oct 2010

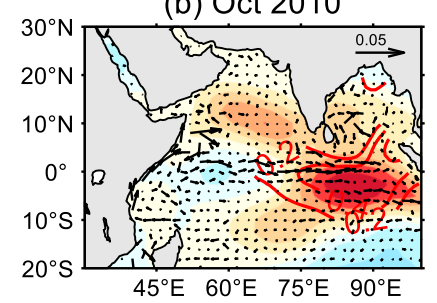

(e) Jan 2011

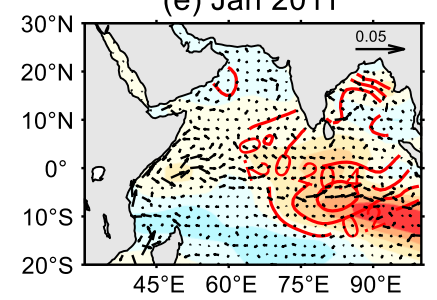

(h) Apr 2011

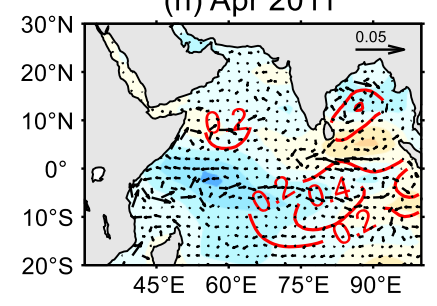

(c) Nov 2010
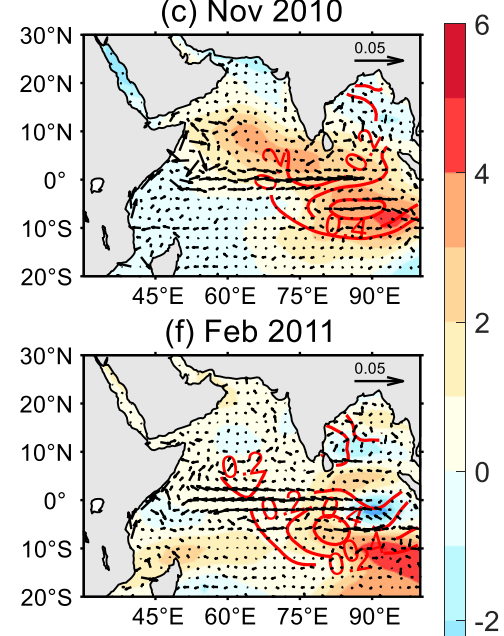

(i) May 2011

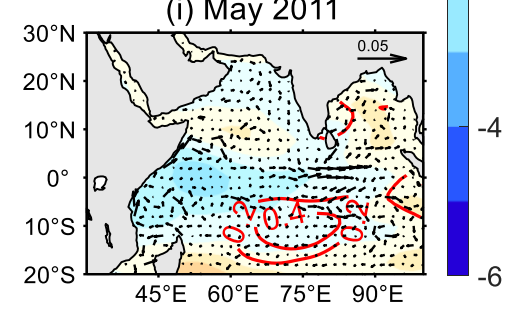

Figure 10. Spatial distributions of monthly mean Argo salinity anomaly (red contours, unit: psu), ocean current (vectors, unit: $\mathrm{m} \mathrm{s}^{-1}$ ) and zonal wind anomaly (shading, unit: $\mathrm{m} \mathrm{s}^{-1}$ ) during 10A11S. Positive zonal wind anomalies indicate westerlies. 
(a) Sep 2016

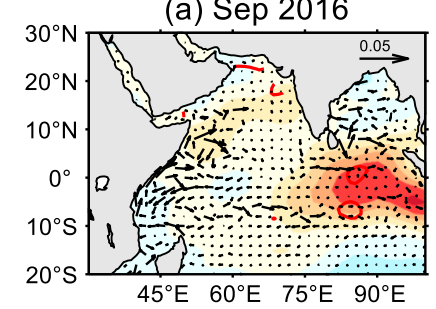

(d) Dec 2016

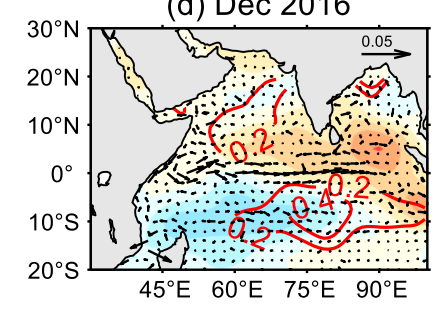

(g) Mar 2017

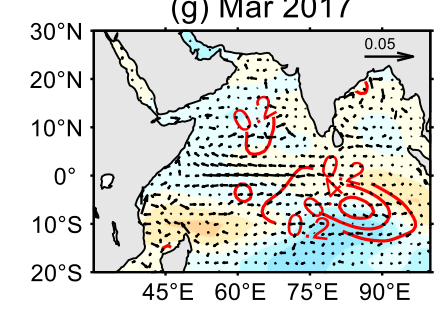

(b) Oct 2016

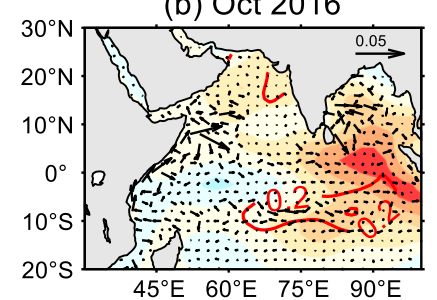

(e) Jan 2017

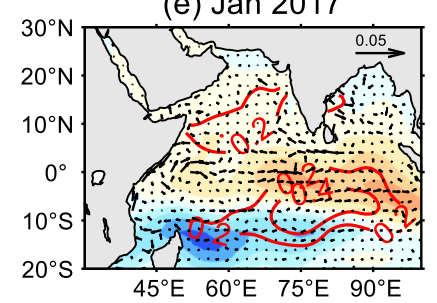

(h) Apr 2017

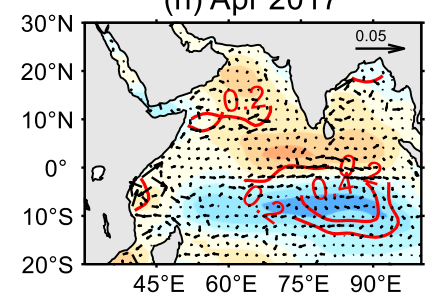

(c) Nov 2016

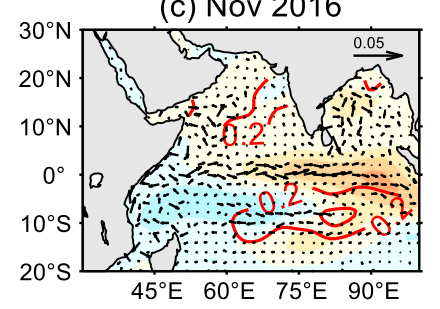

(f) Feb 2017

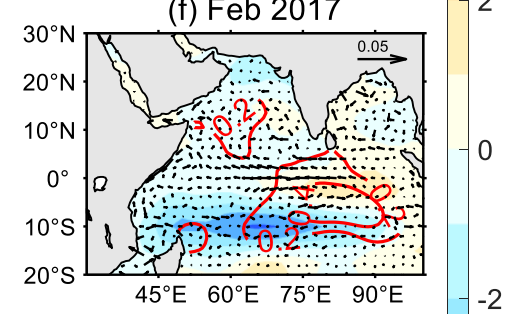

(i) May 2017

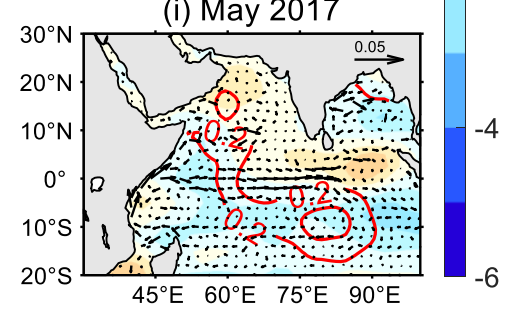

Figure 11. Same as Figure 10, but during 16A17S. 
(a) Sep 2015

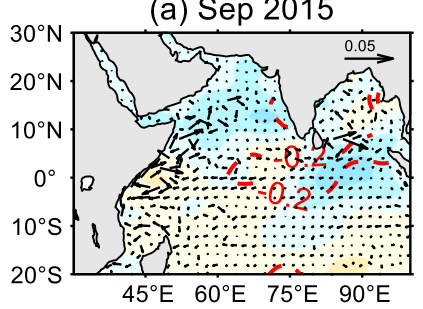

(d) Dec 2015

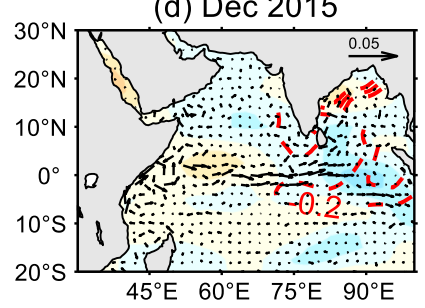

(g) Mar 2016

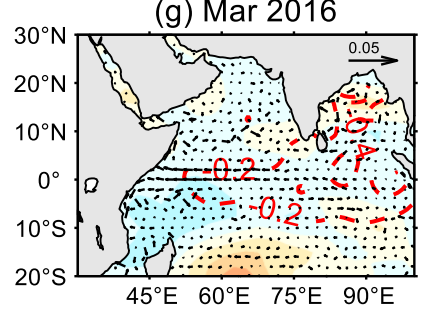

(b) Oct 2015

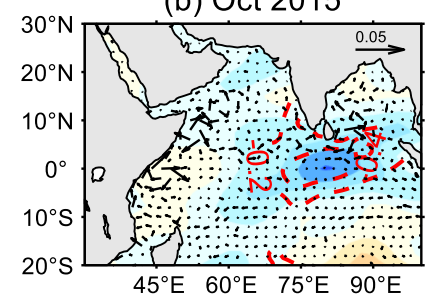

(e) Jan 2016

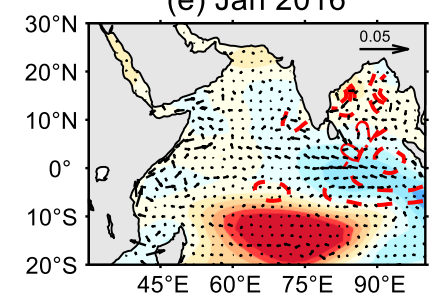

(h) Apr 2016

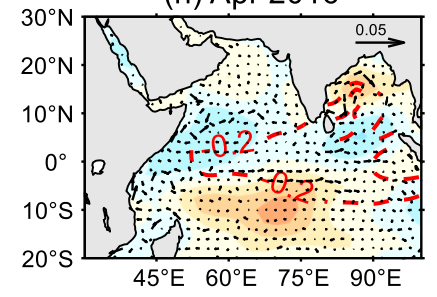

(c) Nov 2015

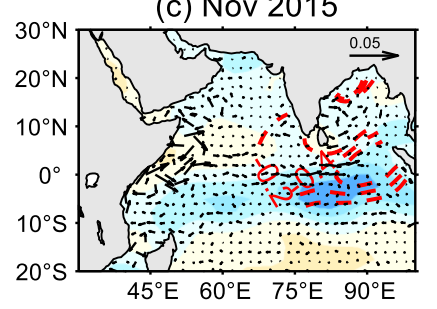

(f) Feb 2016

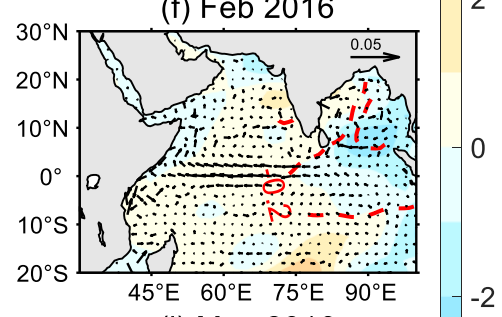

(i) May 2016

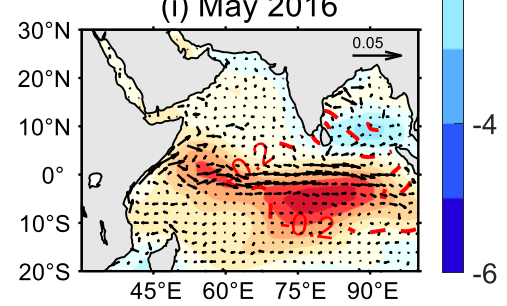

Figure 12. Same as Figure 10, but during 15A16S. 
(a) Salinity budget

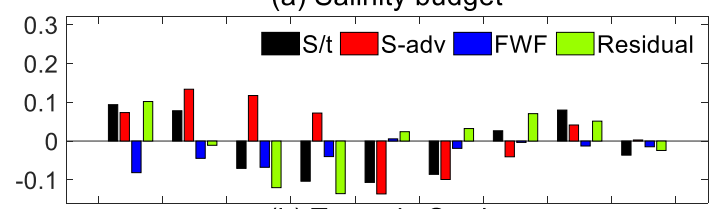

(b) Terms in S-adv

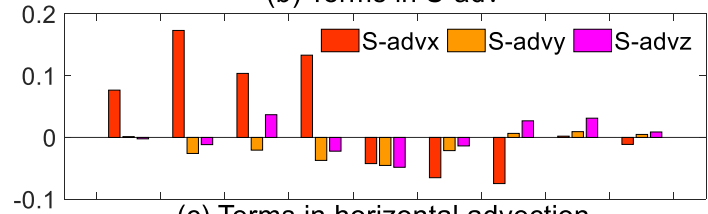

(c) Terms in horizontal advection

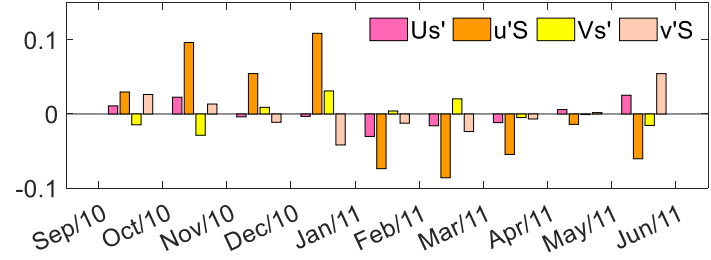

(d) Salinity budget

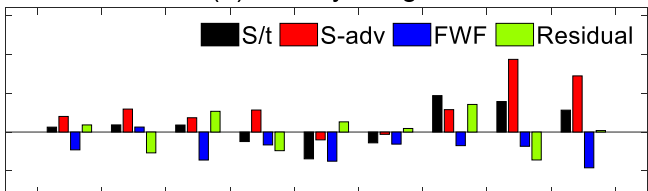

(e) Terms in S-adv

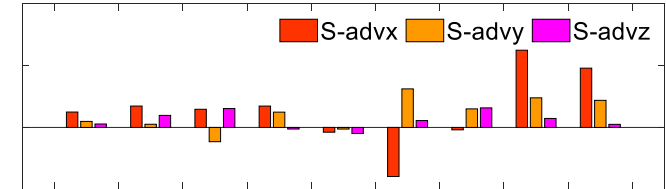

(f) Terms in horizontal advection

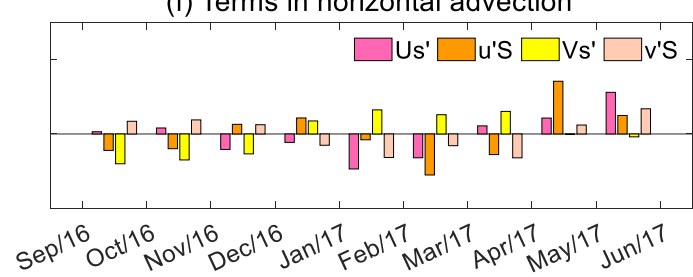

Figure 13. Time series of the averaged anomaly of different budget components (Unit: psu per month) during (a-c) 10A11S and (d-f) 16A17S based on ECMWF ORAS5 salinity data in the main high salinity area. S/t, S-adv, FWF in (a) and (d) represent the salinity anomaly tendency, horizontal advection plus vertical entrainment terms and surface FWF term, respectively. The residual term $\varepsilon$ includes the horizontal and vertical mixing, and the accumulation of errors from the other terms. S-advx, S-advy and S-advz in (b) and (e) represent zonal horizontal advection, meridional horizontal advection and vertical entrainment terms, respectively. Us', u'S, u's', Vs', v'S and v's' in (c) and (f) represent $-\bar{u} \frac{\partial[S]^{\prime}}{\partial x},-u^{\prime} \frac{\partial \overline{[S]}}{\partial x},-u^{\prime} \frac{\partial[S]^{\prime}}{\partial x},-\bar{v} \frac{\partial[S]^{\prime}}{\partial y},-v^{\prime} \frac{\partial \overline{[S]}}{\partial y}$ and $-v^{\prime} \frac{\partial[S]^{\prime}}{\partial y}$, respectively. 

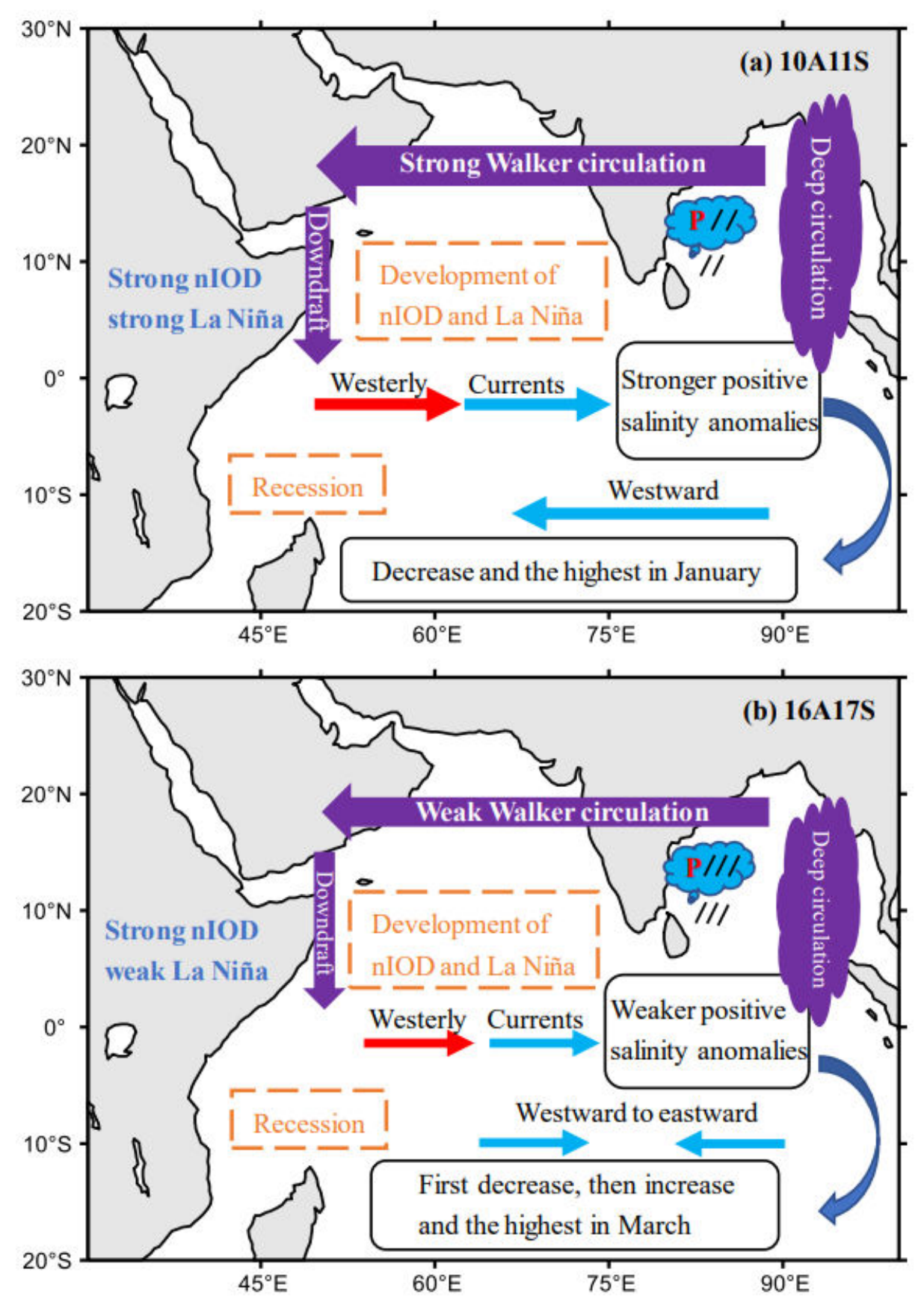

Figure 14. Schematic diagrams of the key processes influencing the extremely high salinity anomalies during (a) 10A11S and (b) 16A17S. The red (blue) arrows indicate the wind (current) fields. The purple arrows indicate atmospheric circulation and red ' $\mathrm{P}$ ' means the precipitation. 